\title{
Carbon Based Electrode Materials and their Architectures for Capacitive Deionization
}

\author{
Bakhtiar Samejo ${ }^{1}$, Shagufta Gul ${ }^{2}$, Suraya Samejo ${ }^{1}$, Naveed Qasim Abro ${ }^{1}$, \\ Nilgun Yenil ${ }^{3}$ and Najma Memon ${ }^{1} *$ \\ ${ }^{1}$ National Centre of Excellence in Analytical Chemistry, University of Sindh, Jamshoro, Pakistan. \\ ${ }^{2}$ College of Chemistry and Chemical Engineering, Ocean University of China, Qingdao, China. \\ ${ }^{3}$ Department of Chemistry, Science and Art Faculty, Celal Bayar University, 45030 Muradiye, Manisa, Turkey. \\ *Corresponding Author Email: najma.memon@usindh.edu.pk \\ Received 05 May 2021, Revised 27 July 2021, Accepted 13 August 2021
}

\begin{abstract}
The effective desalination and purification devices for seawater/ brackish water treatment are crucial in sustainable progress. Techniques that render high salt removal efficiency and water purification ability at low applied potentials play a central role in sustainable water supplies. One of them is capacitive deionization (CDI) which has drawn significant consideration as a promising deionization technology since the last decade. Desalination efficiency profoundly depends on the utilized electrode material. The most widely used CDI electrodes are carbons due to their cost effectiveness and good stability. However, to acquire high electrosorption capacity, extensive researches are reported with modified carbon materials. CDI cell architectures are equally important for practical high salt removal performance. This review focuses on carbon materials in CDI along with other emerging trends in diverse carbon types, e.g., carbon nanotubes and their composites. Various architectures reported in the literature to improve desalination efficiency are also included here.
\end{abstract}

Keywords: Capacitive deionization, Carbon materials, Capacitive deionization cell architectures, Desalination, Hydrochar-based electrodes

\section{Introduction}

In 1960's the capacitive deionization (CDI) was introduced by G.W. Murphy and D.D Caudle at University of Oklahoma [1]. CDI, well known as electrochemical demineralization, is nowadays called an electrosorption system. The first CDI design was a flow through approach in which the activated carbon electrodes were used and brackish/saline water was pumped across electrodes in relation to the externally applied potential as illustrated in Fig. 1 (adsorption and desorption). Adsorption of ions in pores occurred due to electrochemical reactions of specific groups with electrodes.
In 1968 Reid [3] substantiated the technique with commercial electrodes with long life. After that, Johnson and Newman in 1970's proposed desorption of ions for the regeneration of electrodes and removal of brine water [4]. Later, new electrode materials of carbon allotropes were developed, such as activated carbon, carbon cloth, carbon aerogel, carbon nanotube, carbide-derived carbon and graphene, etc. In 2004, the first CDI-based patent work was disclosed [5]. The timeline for the development of CDI-based techniques is shown in Fig. 2. 


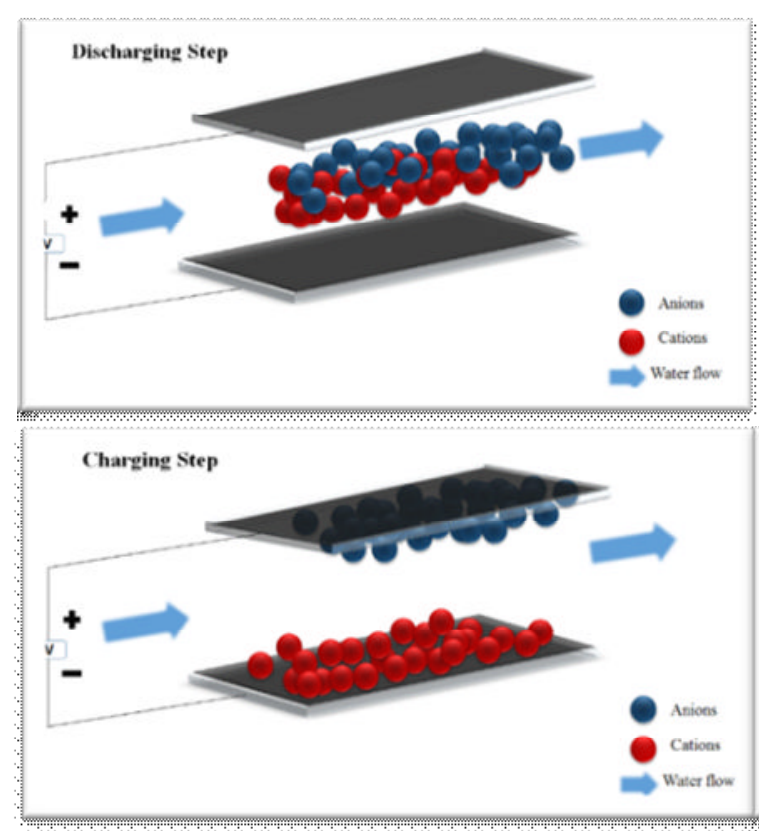

Figure 1. Charging and discharging steps of CDI electrodes [2]

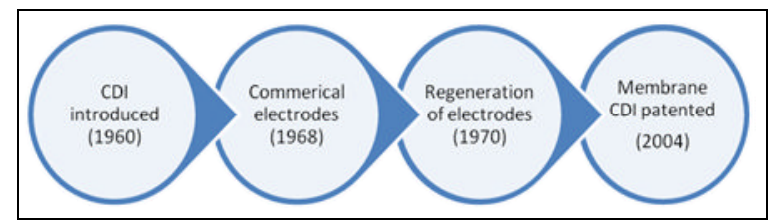

Figure 2. Progress of CDI technology

In recent times, various CDI-based techniques are the focus of attention to researchers due to their energy and water efficient operational costs. Some reviews have been published on CDI of water recently [69]. Table 1 shows a snapshot of various techniques that are currently used for water desalination.

These water desalination techniques utilize diverse technologies, for example, thermally operated [14], chemically activated systems [11], membrane-based pressure driven [15, 16] and electrical processes [17]. In thermal techniques, water is cleaned by evaporation and salts residues are obtained as a by-product [17]. Multiple effect distillation (MED) [18], multistage flash distillation (MSD) [19, 20], thermal vapor compression
(TVC) [21], and mechanical vapor compression (MVC) [22] are just a typical examples. Liquid-solvent extraction (LSE), ion-exchange desalination (I. Ex), gas hydrate (G. Hyd) techniques are entailed in chemically activated techniques where phase transfer of species occurs. In membrane-based technologies, permeable membranes are employed for generating two portions where the unwanted substances such as ions, metal, bacteria and viruses are removed, whereas fresh water is allowed to pass through the membrane, which acts as a filter. Different membrane-based water desalting techniques are categorized as Reverse osmosis (RO) [23, 24] and Membrane distillation (MD) [25, 26]. However, electro-driven desalination techniques include capacitive deionization and electrodialysis, in which these techniques operate using the electric potential to allow the movement of ions to the electrodes [17].

Table 1. Energy and water expenditure of various desalination systems.

\begin{tabular}{|c|c|c|c|c|}
\hline $\begin{array}{l}\text { Desalination } \\
\text { system }\end{array}$ & Mechanism & $\begin{array}{c}\text { Energy } \\
\text { expenditure } \\
\left(\mathbf{k W h} / \mathbf{m}^{3}\right)\end{array}$ & $\begin{array}{c}\begin{array}{c}\text { Water } \\
\text { expense } \\
\left(\mathbf{U S} \$ / \mathbf{m}^{3}\right)\end{array} \\
\end{array}$ & Reference \\
\hline $\begin{array}{l}\text { Brackish } \\
\text { water Reverse } \\
\text { Osmosis } \\
\text { (BWRO) }\end{array}$ & $\begin{array}{l}\text { Pressure } \\
\text { driven }\end{array}$ & $1.5-2.5$ & $0.26-12$ & [10] \\
\hline $\begin{array}{l}\text { Seawater } \\
\text { Reverse } \\
\text { Osmosis } \\
\text { (SWRO) }\end{array}$ & $\begin{array}{l}\text { Pressure } \\
\text { driven }\end{array}$ & $4.0-6.0$ & $0.45-1.71$ & [10] \\
\hline $\begin{array}{l}\text { Multistage } \\
\text { Flash } \\
\text { Distillation } \\
\text { (MSF) }\end{array}$ & $\begin{array}{l}\text { Thermally } \\
\text { driven }\end{array}$ & $2.5-5.0$ & $0.56-1.75$ & [11] \\
\hline $\begin{array}{l}\text { Multiple } \\
\text { Effect } \\
\text { Distillation } \\
\text { (MED) }\end{array}$ & $\begin{array}{l}\text { Thermally } \\
\text { driven }\end{array}$ & $2.5-5.0$ & $0.52-8.0$ & [12] \\
\hline $\begin{array}{l}\text { Liquid-Liquid } \\
\text { Extraction } \\
\text { (LLE) }\end{array}$ & $\begin{array}{l}\text { Chemically } \\
\text { driven }\end{array}$ & 6.0 & 0.40 & [12] \\
\hline $\begin{array}{l}\text { Forward } \\
\text { osmosis (FO) }\end{array}$ & $\begin{array}{l}\text { Concentration } \\
\text { driven }\end{array}$ & $3-8$ & 0.80 & [13] \\
\hline $\begin{array}{l}\text { Electrodialysis } \\
\text { (ED) }\end{array}$ & $\begin{array}{l}\text { Potentially } \\
\text { driven }\end{array}$ & $0.7-5.5$ & $0.6-1 .-5$ & [10] \\
\hline $\begin{array}{l}\text { Capacitive } \\
\text { deionization } \\
\text { (CDI) }\end{array}$ & $\begin{array}{l}\text { Potentially } \\
\text { driven }\end{array}$ & 0.594 & 0.11 & [12] \\
\hline
\end{tabular}


Thermal desalination operation vaporizes brackish/saline water and a residue of salt is obtained by consuming a huge amount of energy. Besides, MSF, MED TVC, MVC, brackish water RO (BWRO), and seawater RO are also used. The amount of energy consumption per liter of desalted water is around 1.5-27.25 kWh of electrical energy. On the other hand, membrane-based techniques have vulnerability issues, for example, bio-fouling, scaling, high energy usage, and water recovery are also low. Although, the efficiency of RO for higher saline water is more effective as compared to the low salinity (below 5000 ppm) desalination process. Electro-driven water desalination techniques utilize low energy and water consumption is also very small as compared to other techniques, whereas CDIbased techniques have the lowest energy consumption. The following section of this review will discuss CDI in detail, which will be followed by electrode materials.

Capacitive deionization is an emerging electrochemical desalination technology for the adsorption of charged species onto porous carbon electrodes. Removal of cations and anions from brackish water occurs by applying a potential difference between the electrodes, causing the formation of an electrical double layer resulting in the adsorption of ions to provide pure water [27]. Compared with the previously used desalination techniques, CDI has advantages such as simple process, being environmentally amicable, and low energy consumption. There is no usage of chemicals or membrane, but ions are adsorbed by applying a direct current $(1-2 \mathrm{~V})$ to electrodes where the electrical double layer (EDL) is formed. The ions are adsorbed on their respective electrodes connected to the source, that is, anions and cations are adsorbed on positive and negative electrodes, respectively. By reversing the current or short circuit, adsorbed ions are discharged as brine water.

The CDI working principle is based on two basic mechanisms: capacitive electrosorption and pseudocapacitive ion intercalation. Capacitive electrosorption is commonly used in which ions are adsorbed by applying an electric potential and the attraction of charged species towards their respective electrodes, causing the formation of EDL by applying an electrical potential, where ions collection is achieved [28]. Hermann von Helmholtz discovered that an interface layer was formed between the electronic conductor (electrode) and an ionic conductor (electrolyte). He realized that co-ions and counter-ions experienced the electrostatic force of attraction and repulsion by charged electrode respectively and in this was formed around two opposing polar layers formed by the electrode and electrolyte interface formation, these charges were electrostatically stored. Charges storage show linearity below electrolytes decomposition voltage. GouyChapman-Stern double layer explained interfacial properties and structures between electrode and electrolyte [29]. This model of the double layer consists of the inner and diffusion region. Ions are directly attached to the electronic conductor surface of the inner region known as the Helmholtz layer, whereas charges present farther from the electrode are attracted linearly depend on the extent of applied electric potential are diffusion layer named as Gouy-Chapman layer. The total capacitance of both inner and diffusion layers can be calculated as series union. Electrical capacitance of interface, $\mathrm{C}_{\mathrm{T}}$, is a sum of two capacitors in series. The total capacitance is given through two layers of both capacitances; thus, it can be calculated like a series union of both the inner Helmholtz layer and diffuse Gouy-Chapman layer (Fig. 3). The electrical capacitance of the interface, $\mathrm{C}_{\mathrm{T}}$, is given as the 
sum of two capacitors in series supplied in Eq. (1).

$$
\frac{1}{C T}=\frac{1}{C M-H}+\frac{1}{C H-S}
$$

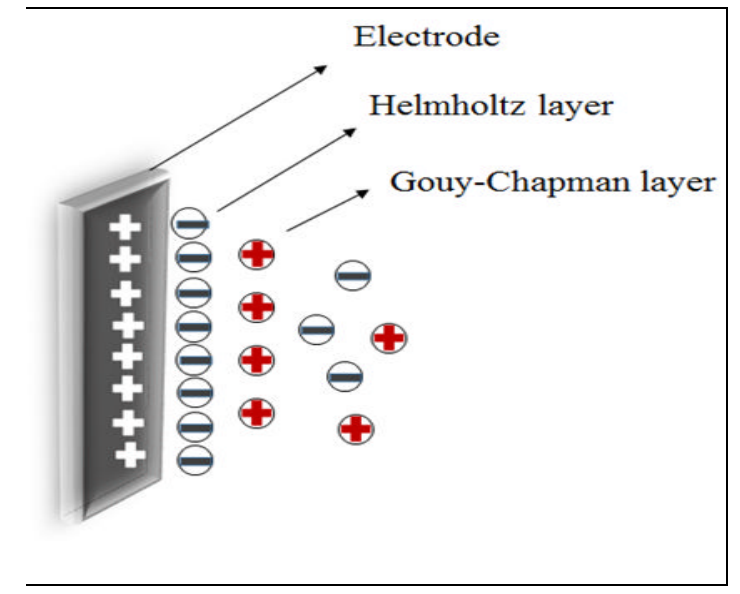

Figure 3. Gouy-Chapman-Stern model of charge distribution [29]

Here, $\mathrm{C}_{M-H}$ and $\mathrm{C}_{H-S}$ are inner double layer capacity onto the surface of electrode $\mathrm{M}$ and the plane of the closest line for ionic species $\mathrm{H}$ (Helmholtz layer) and the capacity of Gouy-Chapman layer, respectively.

Another approach in CDI is pseudocapacitive ion intercalation, in which charged species from salt water exchange reversibly with electrode species through Faradic reaction at the surface of the electrode. In this mechanism, electrode materials other than carbon are used [30]. The electrode materials prefer Faradic reactions, which change the ion electrosorption by ion intercalation or surface oxidation and reduction reactions [31]. Thus, the intercalation electrodes are utilized in this approach and electrode crystallographic sites provide adsorption positions where ions are stored due to redox reactions [32]. Different materials such as MXene [33] and exfoliated molybdenum disulfide [34] have been utilized and other substantials have been studied for CDI and pseudocapacitive desalination.
In addition to basic CDI set-up, modified CDI systems have emerged over time in pursuit of enhanced efficiency; for instance, the addition of ion exchange membranes (IEM) enhanced the efficiency of conventional CDI in which counter-ions are adsorbed, whereas co-ions are expelled that cause lower efficiency of electro-desalination [35]. To overcome this, Andelman introduced membrane capacitive deionization (MCDI) by placing it in front of electrodes [35]. Using modified electrodes, co-ions were blocked, and counter-ions adsorbed more effectively. MCDI consumes low energy from conventional desalination systems at commercially significant levels. Due to its better adsorption and its significant change, the removal of ions by CDI is observed twice as well [36]. Though, co-ions removal can be prevented by using asymmetric electrodes and modification of electrodes with ion-selective functional groups have been offered [37]. Additionally, many other CDI configuration variants listed below have been developed.

\section{Types of CDI cell architectures}

The continuous emergence of innovative architectures for CDI systems has been assimilated in recent years and has introduced numerous distinctive features and unique functionalities in CDI technology. Different CDI cell architectures which have been developed previously are depicted in Fig. 4. The first and historically most extensively used CDI cell geometry contains a pair of carbon electrodes, separated by a spacer through which feed water flows (Fig. 4a). This CDI cell architecture is named flow-by architecture and also called flow-between electrodes CDI [38]. Flow-by CDI has been extensively utilized in diverse works, such as, salt removal from various concentrated feed waters [39], novel carbon electrodes performance consideration $[40,41]$, or fundamental studies of electrosorption 
behavior of porous carbon electrodes [42]. In 1970's, Johnson et al. [4] developed a CDI cell through which the water stream is directed through the porous carbon electrodes and parallel to applied electric potential, as shown in Fig. 4b. Studies of flow cells span the last 40 years until Avraham, who used flow cells in a three-electrode system to study key performance factors such as charging efficiency [42, 43]. Suss et al. [44] investigated the CDI cell performance with flow-through electrodes and hierarchical carbon aerogel monolith (HCAM) electrodes. The results showed a concentration reduction of up to $70 \mathrm{mM}$ of $\mathrm{NaCl}$ feed water when operated in a stopped flow with a mean sorption rate of $1 \mathrm{mg} / \mathrm{g} \times \mathrm{min}$. The benefit of flow-through cell design is that there is no need for a separator layer, thus allowing a separator thickness minimization. Reduced spacer thickness may allow for a more compact cell architecture that has lower cell ionic resistance and faster electrosorption process by decreasing diffusion time leading to the ionic species removal among the electrodes [45].

Another cell architecture with a major variation of basic CDI cell design occurred with membrane CDI (MCDI) progress, and the first demonstration of MCDI was introduced by Andelman et al. [5]. This CDI cell design uses an ion-exchange membrane on each porous carbon electrode as shown in Fig. 4c. An anion exchange membrane (AEM) and a cation exchange membrane (CEM) are bounded with feed water channels in the MCDI geometry, as in the electrodialysis system. The configuration utilized in MCDI is a free standing AEM retained at an anode, and CEM is placed at the cathode [46]. Instead, using the carbon electrodes as structural support, it is conceivable to directly attach a membrane onto the porous carbon electrode, this forms a thinner membrane film than just using a separate membrane [47]. The main advantages of adding membranes to the CDI cell architecture are the increased charging efficiency by blocking co-ions using the membrane and the ability to increase salt adsorption capacity in the electrode macropores [48]. Moreover, membranes can be designed in such a way to adsorb ions selectively amid numerous ionic species that contains the same charge signs, which offer an extra tunability level for complex multi-ions system [49]. In recent years, MCDI has received considerable development in theoretical advancement [48], various materials for membrane, fabrication process and commercialization [47]. Recently, the inverted-CDI (i-CDI) system was formed by modifying the flow-by CDI cell through the utilization of surface treated carbon anode (iCDI in Fig. 4d). Additionally, different electrode materials were modified for i-CDI, such as carbon xerogel anode electrode imbued with a negatively charged surface through chemical surface treatment and pristine carbon xerogel electrode was used as cathode. In this way, the cell demonstrated reverse performance where, the cell charging caused ions desorption from the electrode EDLs and cell discharging caused ions electrosorption. The sorption performance of the i-CDI design was sustained for 600 hours at $0.8 \mathrm{~V}$ with continuous operation.

In 2013, the CDI system innovative architectural design was demonstrated that leveraged carbon flow electrodes or porous carbon slurry electrodes, which can be drove through electrodes sections as seen in Fig. 4g-i (dynamic CDI electrodes design) [12]. The flow electrode CDI (FCDI) concept follows the slurry-based carbon electrodes established for electrochemical energy saving systems, for instance, semi-solid lithium-ion batteries [50, 51], and electrochemical flow capacitors [52]. Furthermore, FCDI has two major benefits compared to static or non-flowable electrodes CDI systems. The first is that continuous desalination is achieved in FCDI, as the 
discharge of activated carbon material (brine water) can ensue in a separate manner downstream of a CDI cell. In traditional CDI cell architectures based on static carbon electrodes, the CDI system can only remove salts for a limited time until saturation of the porous carbon electrodes occurs and then desalination is stopped to regenerate the electrodes for further cycles [46]. However, this alternate operation requires complicated fluidic handling during adsorption and desorption, at different times, from the same spacer amid carbon electrodes. The second is that in FCDI, the uncharged porous carbon particles are introduced into the charging cell, which can efficiently enhance capacitance for effective desalination than static electrodes CDI design. Hence, higher ions removal efficiency can be achieved via FCDI.

A modified FCDI cell architecture was proposed in 2014, which removes ionic species without utilizing the ion exchange membranes or flow type electrodes, as shown in Fig. 4g [53]. Porada et al. [41] presented a new electrode system in motion via moving wires to remove charged species. In this form, graphite rod wires are utilized that are coated with activated carbon and with a possible outer covering of an ion-exchange membrane. The mechanical motion of wires occurs in the feed and brine water. The wire is charged and discharged in a feed and brine stream, respectively. The functioning of the system with several wires cycling between feed-water and brine-water streams may permit continuous salt removal from the feed-water. Advancement is achieved by bridging two different electrodes, battery electrodes (sodium manganese oxide) and the capacitive electrode (porous activated carbon) in a single CDI cell [30] (Fig. 4e). These hybrid CDI systems exhibit good adsorption capacities up to near $31 \mathrm{mg} / \mathrm{g}$ [30], as compared to conventional CDI system, which shows electrosorption capability up to 15 $\mathrm{mg} / \mathrm{g}$ [36].

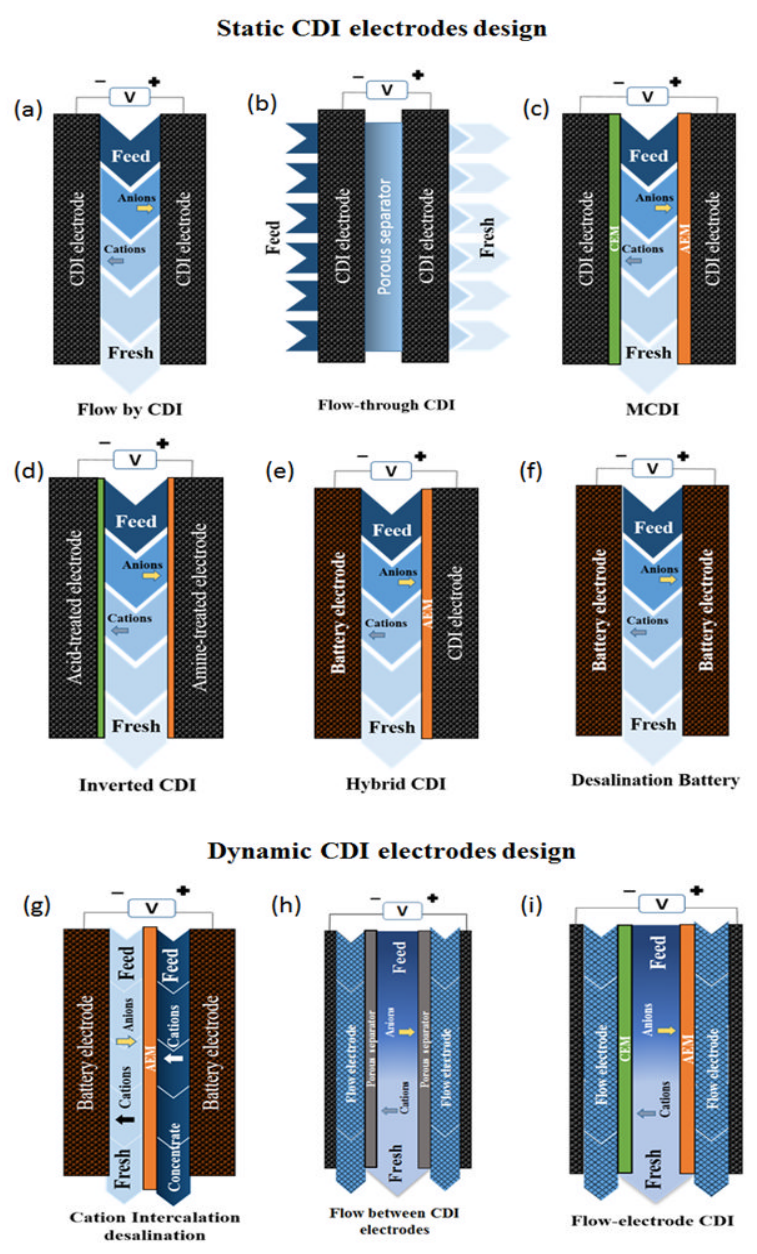

Figure 4. (a)-(d) are static CDI electrode architectures. (e) and (f) architectures use static electrodes which depart from capacitive behavior. (g)-(i) exhibit flow electrodes architectures [36]

Capacitive
development deionization electrodes

Significant developments are seen in improvement for the CDI performance. Different materials can be utilized for the efficient electrode. However, an ideal electrode has the following properties, (1) high specific surface area; (2) electrode stability; (3) capacitance, i.e., adsorption capacity; (4) low cost materials; (5) pore size distribution; (6) plasticity and expandability; (7) oxygenated functional groups. Regeneration of electrodes is done by reversing the electric potential or by a short circuit, then the ions are desorbed as brine 
water [46]. EDL and electrodes regeneration mechanisms also depend on different factors such as porosity, size, surface area, chemical functional groups enhancement. Though, the oxidation of the electrodes reduces desalination efficiency due to its increased oxygen functional groups in the pores of the electrodes, which inversely affect adsorption capacity [54]. However, with oxygen free functional electrolytes, electrodes efficiency may be enhanced hundreds of times to cycle ions adsorption-desorption. This is an essential CDI electrode limitation. Herein, this can be overcome by varying conditions such as nitrogen and argon being inert gases [55]. This is purged in the water stream, carbon electrode oxidation occurs between 0.7 and $0.9 \mathrm{~V}$; to stop this cell potential is reduced [56, 57], chemical treatment of the anode with concentrated negatively charged surface electrolytes [58, 59], the metal oxides doping to the carbon electrode, and ion exchange polymer also stop oxidation reactions which occur at electrodes [59].

Fig. 5 shows the fabrication of freestanding carbon electrodes materials reported in the literature where the diameter of bubbles shows the acquired salt adsorption capacity of individual designed systems and colors of bubbles indicate the influent water concentration. Numerous parameters perform a significant role in the electrosorption process, and the assuring trend of successful application of free-standing carbon electrodes since past years, particularly polymer-based and graphene-based CDI electrodes. The activated carbon takes lead when it comes to treat high concentrations.

CDI performance depends on electrodes' materials. Carbon is highly considered for the material of CDI electrodes due to its various forms, high surface area, better conductivity and cost-efficiency. Various carbon materials including activated carbon (AC) [61], carbon nanofibers [62], carbon nanotubes [63], carbon aerogel [39, 64], and graphene [40, 65] are used as electrodes for CDI operation. Carbon nanofibers, nanotubes, and aerogel are better at the removal of salts in CDI applications. These newly trending materials have complex synthesis procedures and for the CDI process, material production becomes costly at a large scale, which results in limited use instead of outstanding electrosorption. Another amorphous material is activated carbon (AC) which is widely used as an electrode material and is cost effective. AC can be prepared from non-renewable materials such as coal, wood, petroleum residues, lignite and polymers [66]. So, renewable, cost efficient AC electrodes can be made from biomass as well or their byproducts and minimal secondary environmental influence. Increased attention in biomass-based fabricated carbon electrodes for CDI is observed recently. Thus, CDI carbon electrodes synthesis method and their comparative performance with other electrodes used in CDI application are essential to consider. This review paper analyses numerous biomass-based CDI electrode materials, their common synthesis methods and various CDI cell architecture that have been reported for water desalination through capacitive deionization.

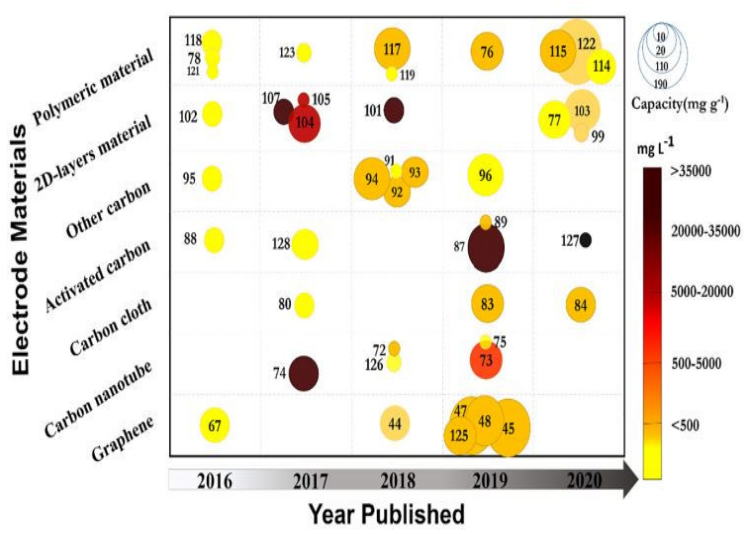

Figure 5. Recent studies of CDI carbon electrodes, including their desalination performances. Here, diameter of bubbles shows the salt removal capacity and color bar shows feed water concentration. Reprinted from [60], copyright (2020), with permission from Elsevier 


\section{Biomass derived carbon electrodes for CDI}

Biomass is biological waste and residue of animals and plants [66, 67]. The sustainable waste-derived carbon electrodes are used in various applications due to very low cost, easily available, easy to prepare and environment friendliness. There are various methods to synthesize AC from biomass, i.e., pyrolysis, hydrothermal carbonization (HTC), activation and salt templating. Different materials including banana peels [68], cotton [69], sugarcane bagasse [70], coconut shell [71], peanut shell [72, 73], cabbage leaves [74], coffee husks [75], biogas slurry and feathers [76] have been utilized to prepare carbon materials for supercapacitors and desalination performance via CDI. The operational principle of supercapacitors and CDI are similar where both rely on the adsorption of charged species in an electrical double layer (EDL). Although, the primary goal of CDI cells is to adsorb ions on the adsorbent from water and not storing the charges like supercapacitors. CDI has straight forward mechanism where ionic species are removed from salted water and are adsorbed on the carbon electrodes connected to power supply for small voltage on them. However, charged species are detained static in supercapacitors to store energy [77]. Different characteristic materials of carbon can be prepared by using different raw substances and synthesis procedure and by altering conditions to yield different surface area, porous morphology, oxygenated functional groups and pore size distribution.

\section{Carbonization methods}

Pyrolysis/carbonization method and activation process

Pyrolysis is the thermal degradation process of hard biomass in the inert atmosphere to produce char and gaseous products at temperatures up to $1000{ }^{\circ} \mathrm{C}$. Pyrolysis conditions are important for the morphological properties of AC (Fig. 6). Though it is a common process to produce porous carbon, yet the synthesized carbon usually has a low surface area. Thus, enhancing the surface area of AC postpyrolysis treatment is common practice. Lado et al. [70] synthesized activated carbon material from sugarcane bagasse fly ash (SBFA) by pyrolysis or thermal activation method at different temperatures. CDI electrodes were prepared from pyrolyzed SBFA carbon material to desalinate brackish water. Increase in surface area by increasing heating temperature at $200{ }^{\circ} \mathrm{C}$ SBFA exhibited a high capacitance of $55 \mathrm{~F} / \mathrm{g}$ with $6.2 \mathrm{mg} / \mathrm{g}$ salt adsorption capacity. Maniscalco et al. [78] prepared electrode materials from the pyrolysis of almond shells at different temperatures (800, 900 and $1000{ }^{\circ} \mathrm{C}$ ) and activated them with $\mathrm{CO}_{2}$ to get $\mathrm{AC} 800$, AC900 and AC1000. Carbon dioxide activation is utilized to create more porous material, enhanced surface area and electrosorption performance. SEM images (Fig. 7-left side) reveals the pore structure of biomass waste derived electrode material. Pore diameters around 10-35 $\mu \mathrm{m}$ were found, and can act as major paths for the spread of ions to micropores and nanopores in the activated carbon. Furthermore, electrosorption process carried at $500 \mathrm{mg} / \mathrm{L}$ initial salt concentration and applied potential of $1.2 \mathrm{~V}$.

The prepared electrodes were saturated completely after $120 \mathrm{~min}$. AC900 exhibited maximum adsorption capacity compared to AC800 and AC1000 as shown in Fig. 7 (rightside). A $19.2 \mathrm{mg} / \mathrm{g} \mathrm{SAC}$ was achieved, while for AC800 and AC1000 SAC was 14.6 and $13.7 \mathrm{mg} / \mathrm{g}$, respectively. BET and $\mathrm{BJH}$ analysis demonstrated that AC900 had high surface area and micropore sites [79]. 


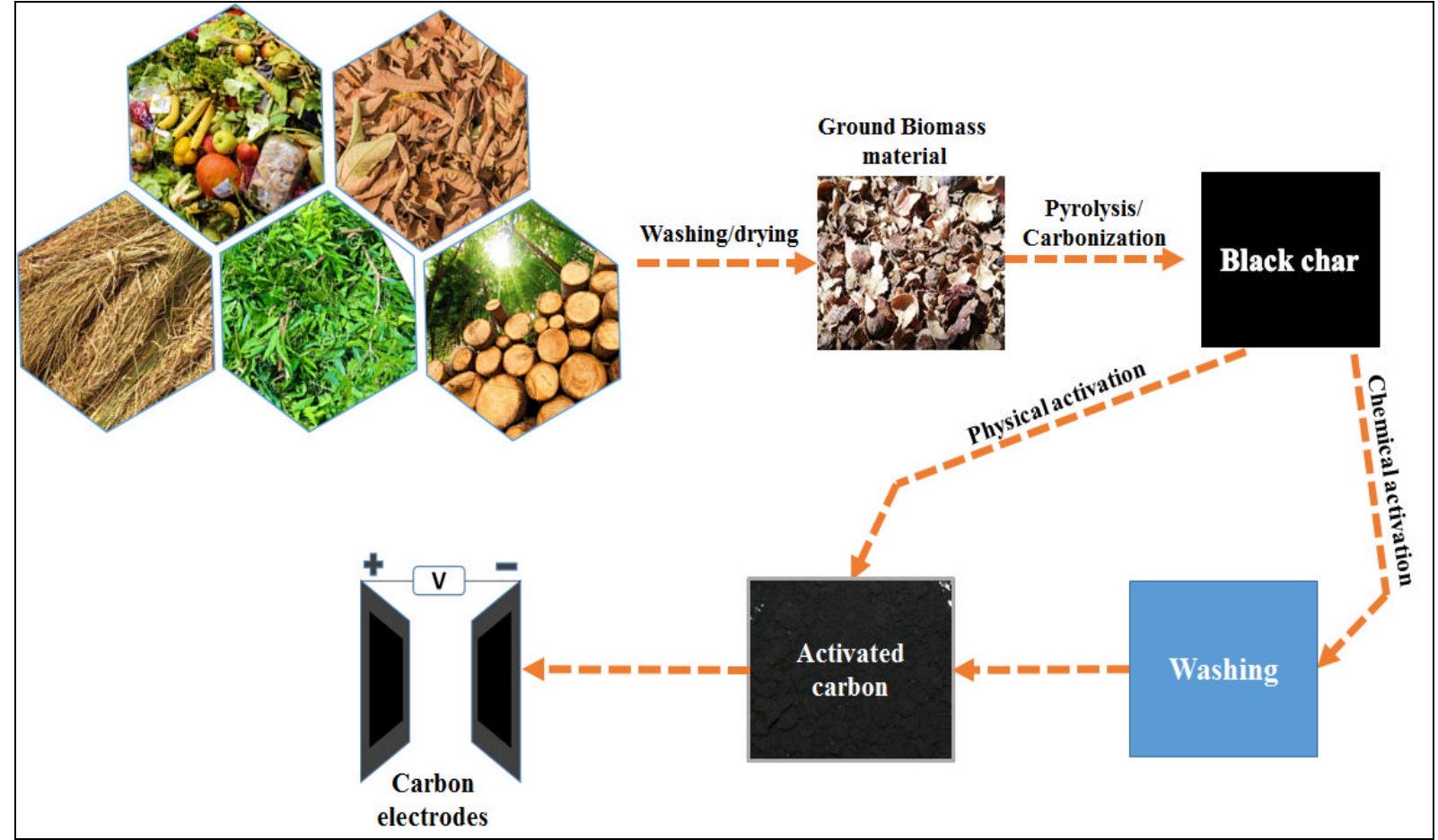

Figure 6. Synthesis route of activated carbon from biomass by pyrolysis and activation process [12]

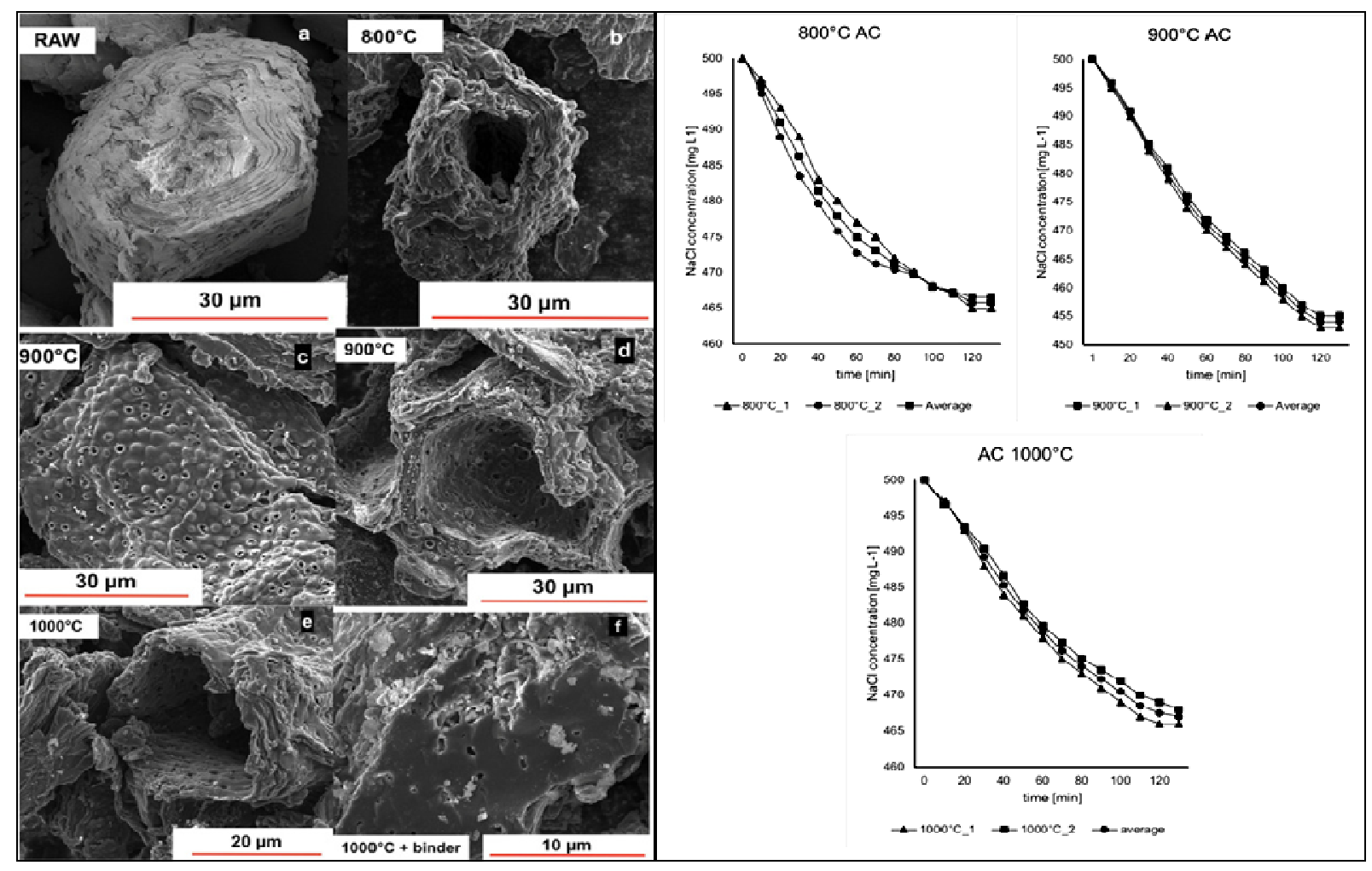

Figure 7. SEM images of raw and pyrolyzed material at 800,900 and $1000{ }^{\circ} \mathrm{C}$ (leftside) and SAC of AC800, AC900 and AC1000 (rightside). Reprinted from [78], copyright (2020), with permission from Elsevier 
Different activation methods are employed, such as chemical and physical activation. Chemical activation is achieved with $\mathrm{KOH}, \mathrm{ZnCl}_{2}, \mathrm{KHCO}_{3}, \mathrm{H}_{3} \mathrm{PO}_{4}, \mathrm{HNO}_{3}$ at a specific ratio of carbon and activating agent, and $\mathrm{CO}_{2}$ or stream is employed to attain physical activation [80]. Generally, chemical activation is preferred over physical activation because it is faster and produces high carbon yields with high surface area, widespread pore distribution, and well-developed porosity [81]. The properties of produced materials depend on the degree of impregnation (ratio of carbon and activating agent). Considerable modification can also be obtained in pore volume by increasing activating agent ratio.

Zong et al. [82] prepared two-dimensional (2D) $\mathrm{N}$-doped amorphous mesoporous carbon nanosheets (ZMCs) derived from zeolite imidazolate framework-8 (ZIF-8) by carbonizing at high temperature by the accumulation of molten salt as a medium. The resulting ZMCs exhibited higher surface area, ample mesopores morphology and rich nitrogen content. The electrosorption results showed that ZMCs electrodes possessed high adsorption capacity up to $46.4 \mathrm{mg} / \mathrm{g}$ at $1.2 \mathrm{~V}$ (DC), compared to ZIF-8 which exhibited $19.1 \mathrm{mg} / \mathrm{g}$, pyrolyzed directly without any medium. Thus, molten salt presence was useful for the amorphous mesoporous carbon nanosheets formation. This enhanced salt adsorption capacity expressed that amorphous carbon nanosheets structure and mesoporous morphology eased the transportation of ions during the desalination process. Furthermore, AFM images showed that ZMCs have a thin nanosheet structure with a thickness around 3 $\mathrm{nm}$ (Fig. 8). ZMCs formation mechanism derived from molten salt contain ZIF-8 as dissolution growth occurs through the salttemplating method. It was distinguished that no residue of carbon obtained while pyrolyzing the ligand (2-methylimidazole) in the presence of $\mathrm{LiCl}-\mathrm{KCl}$ at a high temperature of $800{ }^{\circ} \mathrm{C}$ because of ligand (BP: $268^{\circ} \mathrm{C}$ ) volatilization. The solid salt composite mixture begun to melt above $353^{\circ} \mathrm{C}$. The high polarity of liquid salts melted the ZIF-8 ligand (2-methylimidazole). Meanwhile, molten salt inhibited the area for ligand derivatives in polymerization, pyrolysis and demixing procedure, where the salt template generated carbon nanosheets with abundant mesopores. Moreover, ZMCs surface showed wrinkles which provided more active sites to accelerate transportation of ions to increase CDI desalination performance.
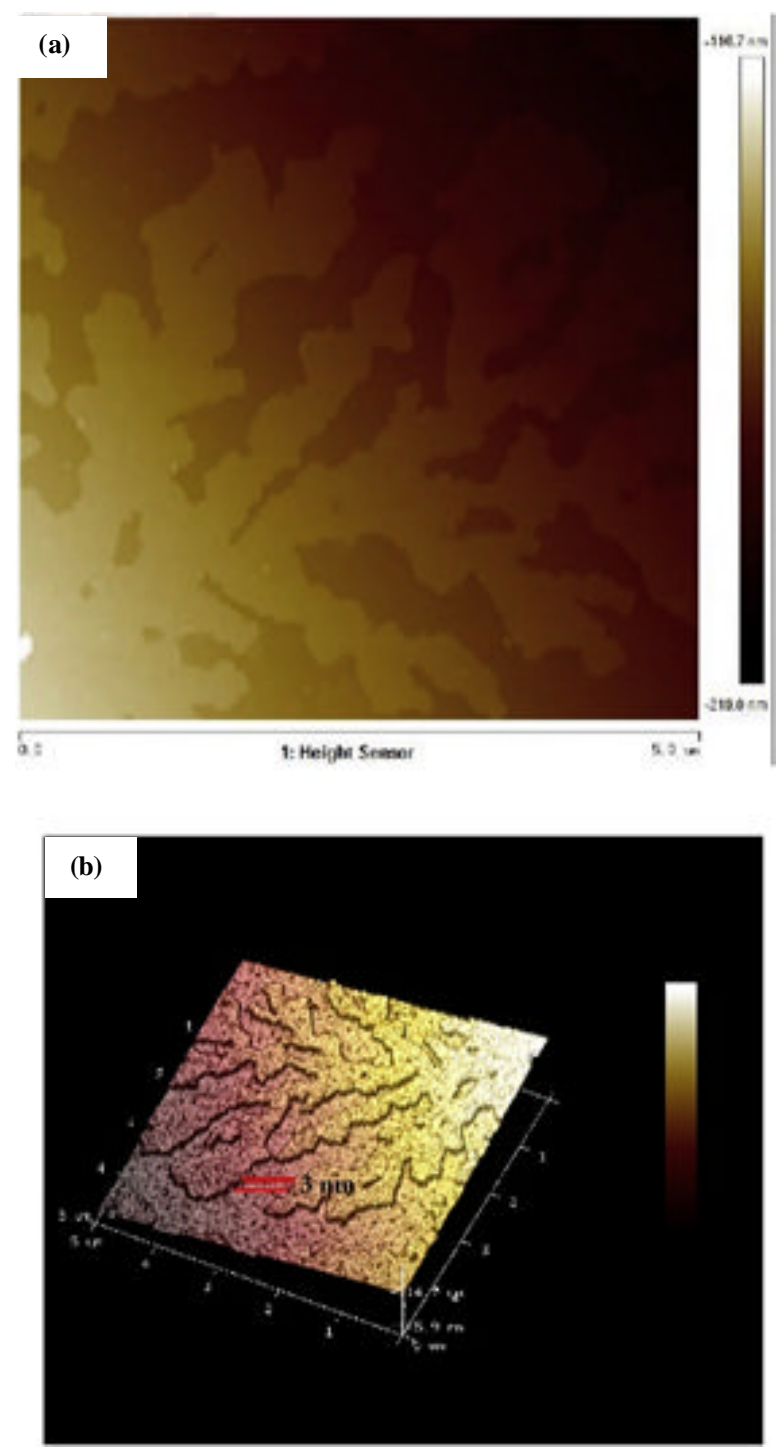

Figure 8. 2D (a) and 3D (b) AFMimage of ZMCs. Reprinted from [82], copyright (2020), with permission from Elsevier 


\section{Hydrothermal carbonization}

Hydrothermal carbonization (HTC) is a thermochemical process of soft biomass conversion into carbon material that uses subcritical water as a reaction medium [83, 84]. HTC is a mixture of biomass material (carbon precursor) and water thermally treated at modest temperatures (180-250 $\left.{ }^{\circ} \mathrm{C}\right)$ over autogenous pressure. HTC synthesis process can convert wet biomass into carbon without pre-drying by applying low temperature, it is environmentally friendly and can be produced at low cost [85]. This process lowers the oxygenated functional groups in feedstock through decarboxylation and dehydration. To enhance the porosity of HTC's chemical activation method, the synthesis method is illustrated in Fig. 9.

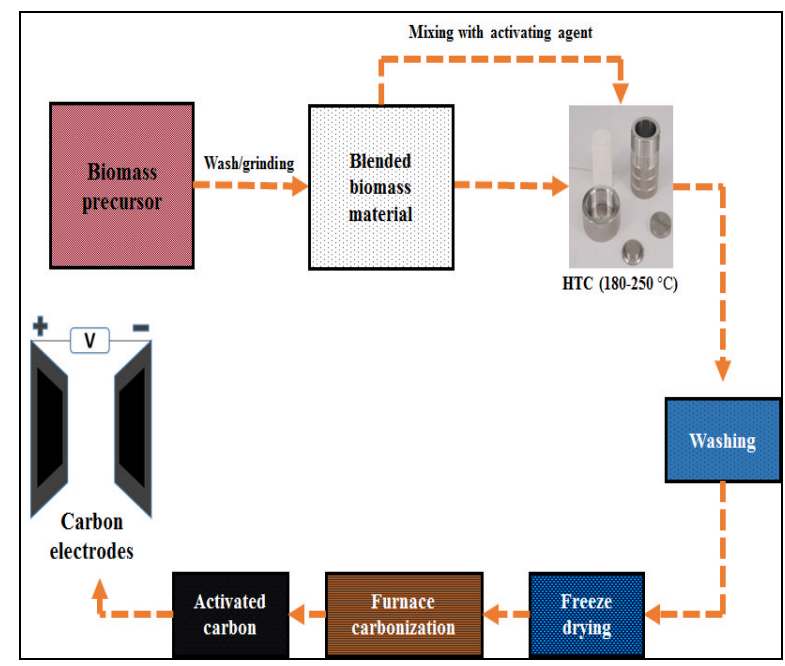

Figure 9. Synthesis process of activated carbon from biomass through hydrothermal carbonization followed by activation process [12]

Wang et al. [86] prepared graphitic porous carbon nanosheets (GPCS) by hydrothermal carbonization followed by pyrolysis. They used wheat straw source material for pre-carbonization, took wheat straw $1.5 \mathrm{~g}$ and added $2.5 \mathrm{~mL} \mathrm{H}_{2} \mathrm{SO}_{4}$ in $50 \mathrm{~mL}$ deionized water, and then stirred the mixture for $20 \mathrm{~min}$. The obtained solution was transferred to Teflon lined container at $180{ }^{\circ} \mathrm{C}$ for $12 \mathrm{~h}$. The autoclave was left to cool down at room temperature, and the pre-carbonized material was washed several times with deionized water until the neutral $\mathrm{pH}$ was achieved. Pre-carbonized wheat straw was further dried at $80{ }^{\circ} \mathrm{C}$ in the oven. GPCS synthesis was achieved by mixing $1.0 \mathrm{~g}$ wheat straw (pre-carbonized) and $2.5 \mathrm{~g} \mathrm{ZnCl}_{2}$ into the $20 \mathrm{~mL}$ of $\mathrm{FeCl}_{3}(2.5 \mathrm{M})$ solution. The composite solution was stirred and evaporated to have viscous at $80{ }^{\circ} \mathrm{C}$ and dried in an oven at $80{ }^{\circ} \mathrm{C}$ to acquire a powder. This solid powder was pyrolyzed at $700{ }^{\circ} \mathrm{C}$ for $1 \mathrm{~h}$ in the presence of nitrogen gas. $\mathrm{HCl}(2 \mathrm{M}), \mathrm{HF}(10$ wt $\%$ ) and distilled water solutions were used to remove metal species and silica, respectively and it was dried at $80{ }^{\circ} \mathrm{C}$ to obtain finely GPCS. Furthermore, the authors also succeeded in the comparative study between pre-carbonized material with and without $\mathrm{ZnCl}_{2}$ and $\mathrm{FeCl}_{3}$ termed as porous carbon (PC). The pre-carbonized wheat straw pyrolyzed individually with $\mathrm{ZnCl}_{2}$ and $\mathrm{FeCl}_{3}$ was named as activated porous carbon (APC) and catalyzed carbon (CC), respectively. Measurements of dynamic contact angle for GPSC, PC, APC and CC were conducted and wetting phenomenon. GPSC exhibited good hydrophilicity around $36.3^{\circ}$, whereas PC, APC and CC shown poor hydrophilicity, i.e., larger contact angle $129.0^{\circ}, 79.8^{\circ}$, and $111.7^{\circ}$. The contact angle of the GPSC was decreased to $15.1^{\circ}$ after a half-second by disappearing the water droplet, while the contact angle and the droplet hardly altered in PC, APC and CC due to poor wettability as depicted in Fig 10. In the electrosorption process, GPSC showed a novel structure, high surface area and good electrical conductivity with high salt adsorption capacity of $19.3 \mathrm{mg} / \mathrm{g}$ and SAR of $0.48 \mathrm{mg} / \mathrm{g} \times \mathrm{min}$, in a $500-\mathrm{ppm}$ solution at an applied potential of 1.2 V. Moreover, GPSC electrodes showed decent regeneration potential. GPSC removal efficiency towards metals was more than $90 \%$ in 100-ppm solution at a potential difference of $1.2 \mathrm{~V}$. 


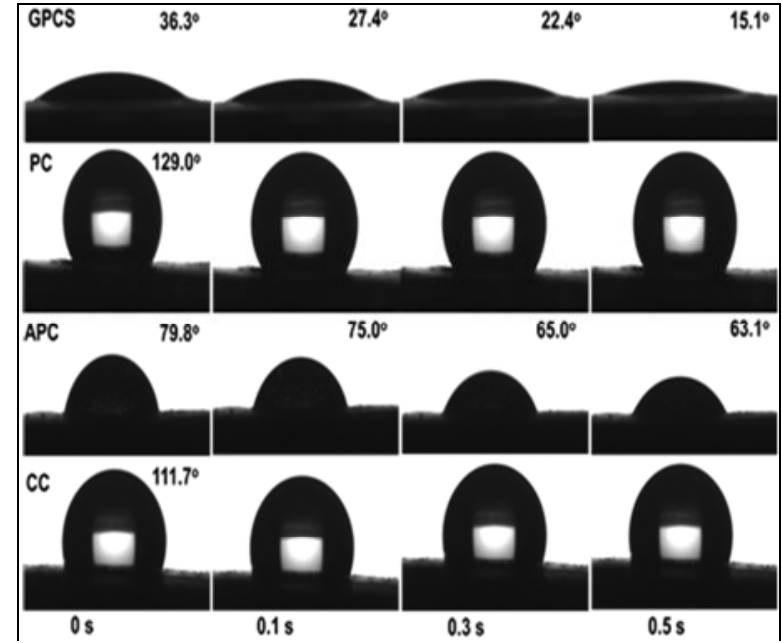

Figure 10. GPCS, PC, APC and CC surface optical micrographs of water contact angles. Reprinted from [86], copyright (2020), with permission from Elsevier

Shou-Heng et al. [87] developed biocarbon material derived from sugarcane bagasse biowaste (SB) through carbonization followed by activation and offered it by utilizing a microwave-assisted process with $\mathrm{KOH}$ in the presence of $\mathrm{CO}_{2}$. They also studied the effect of microwave irradiation $(500-800 \mathrm{~W})$ in SBs morphology, mesoporosity ratio surface area, as illustrated in Fig. 11a. The prepared material attained different desalination performances due to differences in surface area and mesoporosity. The $\mathrm{SB}-\mathrm{CO}_{2}-700$ material activated at irradiation of $700 \mathrm{~W}$ exhibited a higher ratio of mesopore to total pore volume with a high surface area of $764 \mathrm{~m}^{2} / \mathrm{g}$. Raman spectra of the synthesized biocarbon via using microwave power $(500-800 \mathrm{~W})$ under $\mathrm{CO}_{2}$ flow exhibited two broad bands near 1358 and $1588 \mathrm{~cm}^{-1}$, representing with $\mathrm{D}$ (disordered structures) and $\mathrm{G}$ (graphitic crystalline) signals, respectively as shown in Fig. $11 \mathrm{~b}$. $\mathrm{SB}-\mathrm{CO}_{2}$ 700 shown a greater intensity ratio compared to others. This may be due to highly porous and disordered structure formation in these materials through the activation process. The salt removal efficiency of SB-CO $\mathrm{CO}_{2}-700 \mathrm{CDI}$ electrodes possessed $11.4 \mathrm{mg} \mathrm{g}^{-1}$ at $1.2 \mathrm{~V}$ applied voltage.

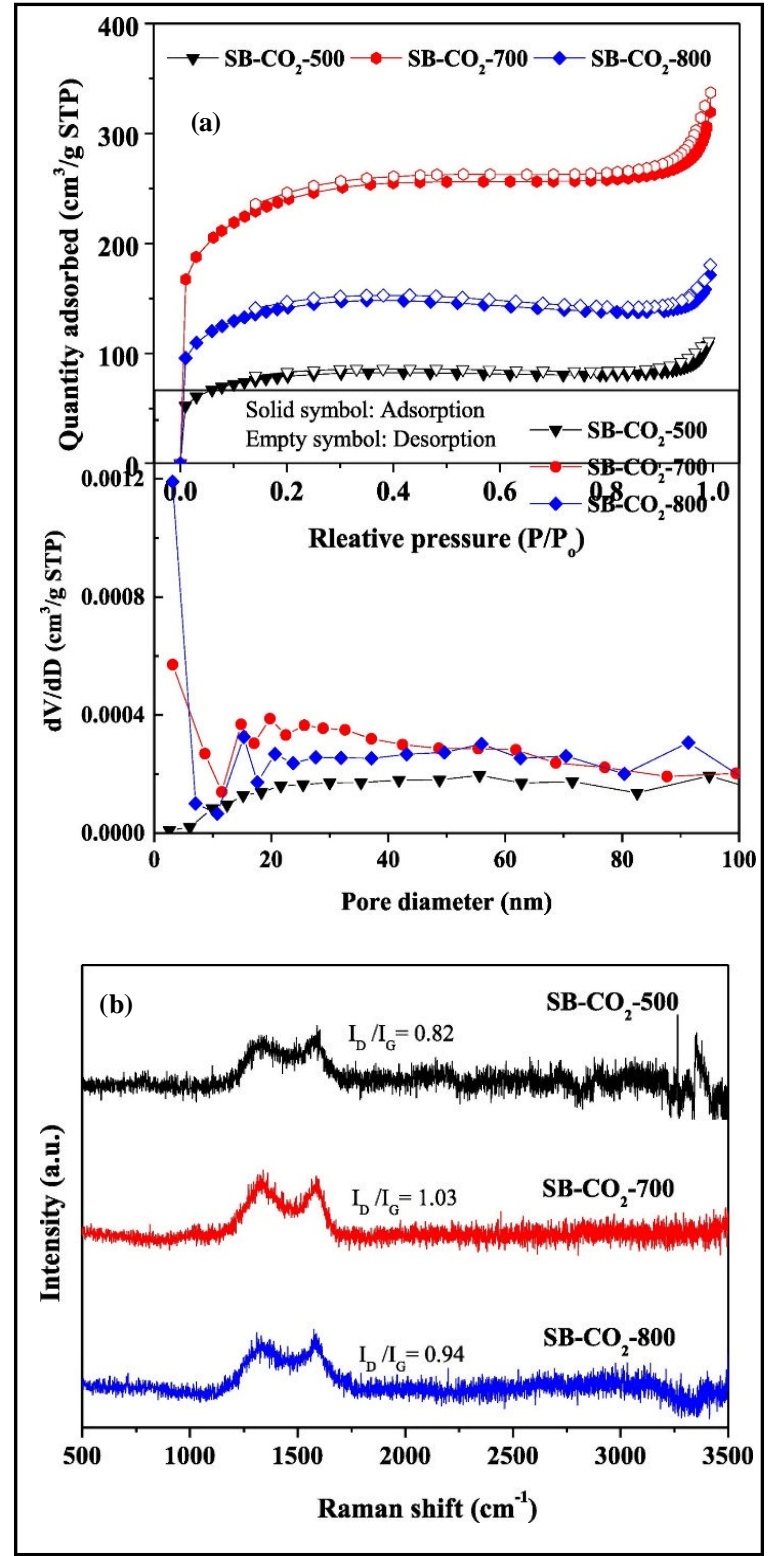

Figure 11. (a) $\mathrm{N}_{2}$ adsorption and desorption isotherms and pore size distribution of $\mathrm{SB}$ at different microwave power under $\mathrm{CO}_{2}$ atmosphere, and (b) Raman spectra of $\mathrm{SB}-\mathrm{CO}_{2} .500, \mathrm{SB}-\mathrm{CO}_{2.700}$ and $\mathrm{SB}-\mathrm{CO}_{2.800}$ microwave power. Reprinted from [87] copyright (2020), with permission from Elsevier

Mohamed et al. [88] fabricated microporous carbon spheres (CSs) through a facile green process with cost efficient source materials. They took $4.0 \mathrm{~g}$ of dissolved glucose and immersed it in a $70 \mathrm{~mL}$ autoclave of Teflon lined steel. The autoclave was furnaced at $200{ }^{\circ} \mathrm{C}$ for $40 \mathrm{~min}$ and kept at this temperature for $8 \mathrm{~h}$. The resulting product was 
collected after cooling, filtered off and washed with distilled water and ethanol, severally. The material was dried at $80{ }^{\circ} \mathrm{C}$ for overnight. Furthermore, CSs were calcined at 700, 800 and $900{ }^{\circ} \mathrm{C}$ in a tube furnace for $4 \mathrm{~h}$ under an inert atmosphere (Nitrogen gas). The synthesized CSs were named according to their carbonization temperatures in the synthesis process, for instance, CS700, CS800 and CS900, as illustrated in Fig. 12. It was found that CS800 possessed a high capacitance of $71 \mathrm{~F} / \mathrm{g}$ and low internal resistance with a high surface area of $361 \mathrm{~m}^{2} / \mathrm{g}$ than CS700 and CS900. The salt adsorption capability of CS800 was attained to be 10.3 $\mathrm{mg} / \mathrm{g}$ at $1.6 \mathrm{~V}$. It also revealed good electrode regeneration performance.

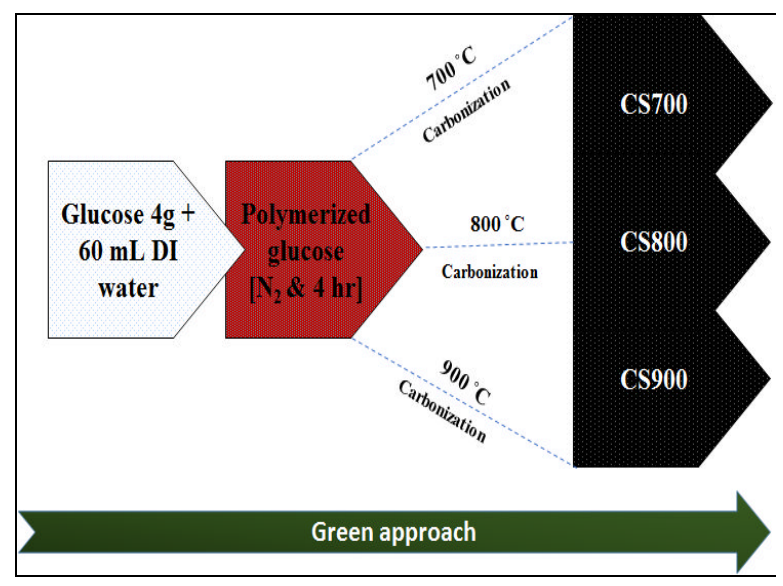

Figure 12. Synthesis process of CSs through green approach [85]

Xie et al. [85] prepared HTC from citrus peel followed by chemical activation using a small amount of activating agents $\left(\mathrm{ZnCl}_{2}, \mathrm{H}_{3} \mathrm{PO}_{4}\right.$ and $\left.\mathrm{KOH}\right)$. The properties of synthesized porous carbon are changed using different activating agents, i.e., different electrochemical, structural and electrosorption properties. However, $\mathrm{ZnCl}_{2}$ exhibits enhanced properties than $\mathrm{KOH}$ and $\mathrm{H}_{3} \mathrm{PO}_{4}$. These improved properties were due to the addition of $\mathrm{ZnCl}_{2}$ in the hydrothermal step, where the degradation of cellulose and carbon aromatization leading to high specific surface area and pore volume of $323 \mathrm{~m}^{2} / \mathrm{g}$ and 0.197 $\mathrm{m}^{3} / \mathrm{g}$, respectively, charge efficiency, highest adsorptive capacity and salt removal performance. Furthermore, Zhang et al. [89] produced a 3D honeycomb-like structure porous carbon from corncob waste material through hydrothermal carbonization followed by chemical activation using $\mathrm{KOH}$ and $\mathrm{CDI}$ electrode was prepared from resultant carbon and utilized to remove chromium (VI) from water. Surface area and pore volume were enhanced via $\mathrm{KOH}$ activation and different activation temperatures.

\section{Doping of carbons with hetero-atom}

Salt templating is another known method used to convert the biomass material to activated carbon. Heteroatom-doped carbon can be acquired in this simple and effective way. Herein, heteroatom precursor is added into carbon precursor and are mixed with the low melting salt to let the carbon heteroatom doping before pyrolysis and this low melting salt serve as a solvent and a template simultaneously [90]. Salt templating is applied to prepare heteroatom doped porous carbon, which cannot be acquired by chemical or physical activation [91]. Carbon materials may have doped heteroatoms such as boron, nitrogen, phosphorus and sulfur as illustrated in Fig. 13. The modified carbon heteroatoms exhibit enhanced electrical conductance and wettability, which show improved electrochemical and desalination performance [92]. Among these different heteroatoms, nitrogen is considered more suitable because it is similar to carbon in atomic size and valence shell [93, 94]. It is observed that nitrogendoped carbon material contains more defects that generate more available surface area and capacitance improves capacitive performance [93]. The nitrogen can be introduced in different materials at low cost, i.e., sucrose, glucose [95], glucosamine [95] and chitosan [92] can be used for the preparation of $\mathrm{N}$ doped carbon substances. 


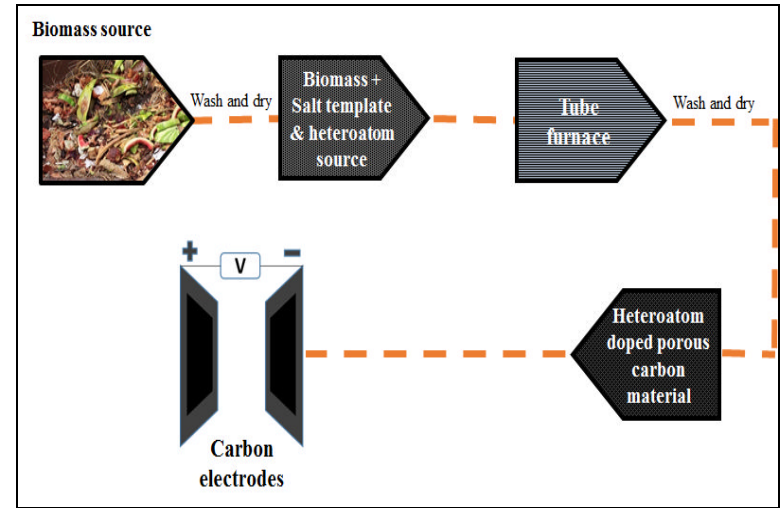

Figure 13. Synthesis route of heteroatom-doped carbon material from biomass through salt templating approach [12]

Shichao Tian et al. [96] prepared nitrogen-doped highly mesoporous carbon (NOMC) material along with mesochannels through a self-assembly procedure and NOMC's electrochemical and structural characteristics were studied carefully. The Ndoping was utilized to increase the CDI electrosorption performance through the pseudocapacitance generation and the electrical conductance and hydrophilicity improvement. However, rapid ions transportation in the pore channels were seen in electrode materials of highly ordered mesoporous structure, enhancing electrodes surface area utilization and desalination performance. The surface structure and pore size of NOMC ordered mesoporous structure was analyzed by TEM as illustrated in Fig. 14. The large surface of the regular line structure exposed high order of mesoporous carbon material. In Fig. 14a, white lines corresponded to mesoporous channels with good organization. Moreover, lamellar assembly with jagged edge was produced, this would enhance surface area adsorption sites and facile charge transfer during the adsorption process. The tube-like meso channels were regularly associated along the same way within individual particles, as shown in Fig. 14b. Thus, delivering a diffusion direction for electrolytes. NOMC exhibited well distinct meso channels running resembles each other and obviously disclosing an extended range order. Additionally, NOMC electrode adsorption capacity was obtained $26.2 \mathrm{mg} / \mathrm{g}$ with a good electrode regeneration process, exposed as a potential electrode material for CDI performance.
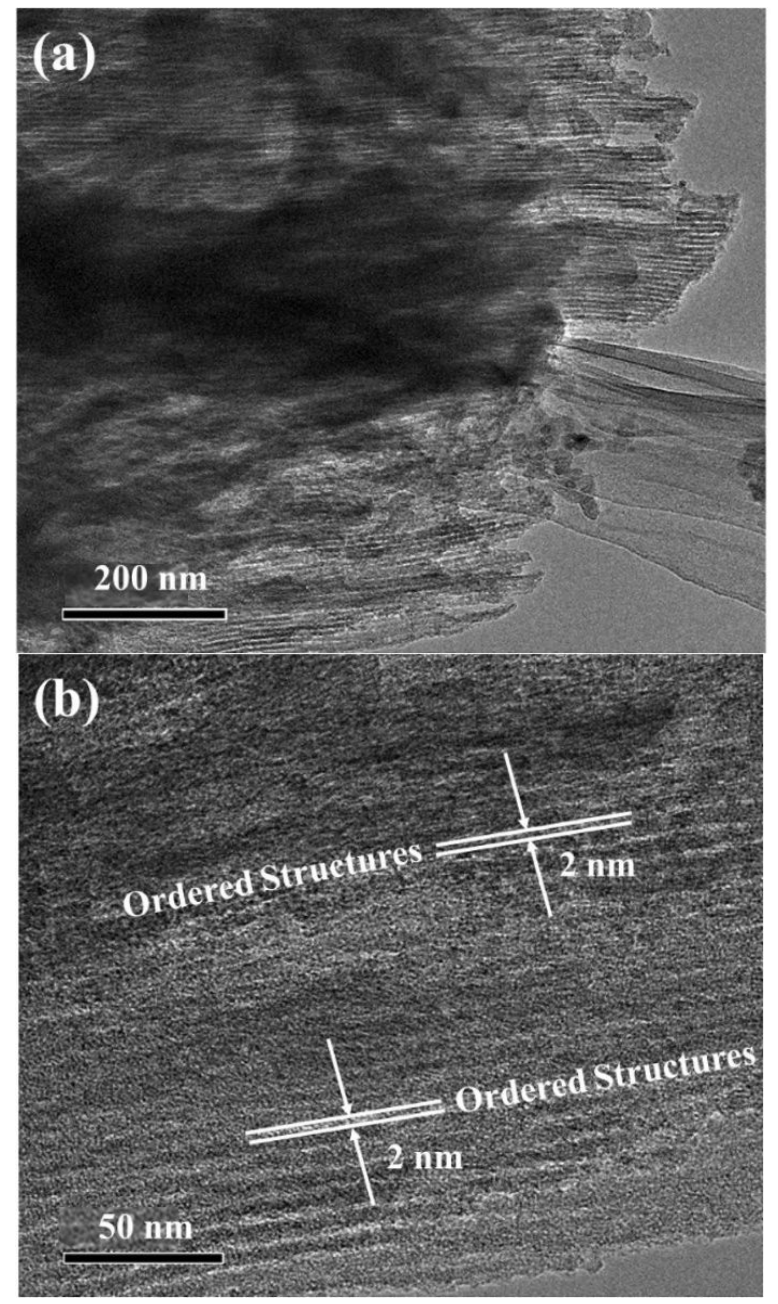

Figure 14. NOMC TEM images at (a) low resolution and (b) high resolution. Reprinted from [96], copyright (2020), with permission from Elsevier

Porada et al. [95] prepared biomasses derived nanoporous heteroatom doped carbon materials using bottom-up salt template method with nitrogen and sulfur dopants. In this method, sulfur was obtained from 2thiophenecarboxylic acid (TCS), $\mathrm{ZnCl}_{2}$ as a salt template and cesium acetate as an activating agent. Different activation temperatures and varying salts produce 
modified surface morphology, surface area and pore structure. Nitrogen-doped carbon $(\mathrm{N}$ wt $1 \%$ ) yielded surface area up to $2830 \mathrm{~m}^{2} / \mathrm{g}$ with a salt adsorption capacity of $15.0 \mathrm{mg} / \mathrm{g}$ at low voltage as $1.2 \mathrm{~V}$ using $5 \mathrm{mM} \mathrm{NaCl}$ solution. Another approach to obtain heteroatom-doped carbon material can be acquired by functionalizing activated carbon with heteroatom dopant. Zhao et al. [97] synthesized $\mathrm{N}$-doped carbon (NC) by 1.66 wt\% nitrogen content with soybean shell derived microporous precursor through a $\mathrm{KHCO}_{3}$ assisted pyrolysis method. The further modification was attained using sulfonic groups in aryl diazonium salt solution with $\mathrm{N}$ doped porous carbon (NPC) to achieve sulfonyl-functionalized $\mathrm{N}$-doped porous carbon (SNPC). The specific capacitance of soybean shell derived $\mathrm{N}$-doped carbon (NC), NPC and SNPC were obtained as 156.5, 165.2 and $215.3 \mathrm{~F} / \mathrm{g}$. Herein, capacitance of SNPC was enhanced due to occurrence of sulfonyl groups $\left(-\mathrm{SO}_{3}\right)$. The salt adsorption capacity (SAC) of NPC and SNPC was achieved at $16.0 \mathrm{mg} / \mathrm{g}$ and $15.5 \mathrm{mg} / \mathrm{g}$, respectively, using $40 \mathrm{ppm} \mathrm{NaCl}$ solution. SAC of NPC is a higher preference due to its high surface area and pore structure. Moreover, the relative salt adsorption capacity (SAR) of SNPC is higher than NPC 0.52 and $0.44 \mathrm{mg} / \mathrm{g} \cdot \mathrm{min}$, respectively. SNPC has acquired a higher SAC of $43.3 \mathrm{mg} / \mathrm{g}$ than reported novel carbonbased electrodes. The biomass derived porous carbon electrode has acquired the highest SAC of 38.0 and $57.13 \mathrm{mg} / \mathrm{g}$ through membranecapacitive deionization (MCDI) and $\mathrm{Cu}$ (II) removal from $\mathrm{CuCl}_{2}$ solution. The reported studies of biomass-based CDI carbon electrodes have salt removal capacity is comparable with novel materials. Other researchers such as, Evans et al. [98] reported polyaniline carbon CDI electrodes with a stable life cycle and ZU et al. [99] performed 3D-intercalated graphene sheet-shape nanocomposite architectures.

\section{Electrode materials development for capacitive deionization}

The CDI electrodes development has been seen over the past decades to enhance the carbon electrodes performance for the supercapacitors and desalination. Various electrodes can be prepared from a large family of carbons, signifies a wide range of materials composed of carbon element. The crystalline and amorphous structure of carbon have their characteristic properties, crystalline allotropes are graphite, diamond and fullerenes. Due to crystal structure, they are not good materials for adsorption because of their lack of specific surface area. Whereas, amorphous carbon has randomly arranged carbon atoms that tend to crosslink with each other and gives welldeveloped porous structure [100]. These amorphous materials are known as activated carbon and because of their porosity, these are widely used as adsorbents for color, odor, organic impurities, capacitance and desalination process [80]. However, carbon materials had been used as an adsorbent because of the highly promising porous structure for water treatment before CDI. Various other carbon materials are developed with certain patterns of carbon atoms, such as sheets (graphene) and tubes (carbon nanotubes). The materials with these patterns have distinctive properties of high electrical conductivity, large surface area and good thermal conductivity. These materials and their applications in CDI will be discussed here.

\section{Activated carbon}

Activated carbon (AC) has been used widely as an adsorbent in various applications. The synthesis process of AC is mainly achieved by pyrolysis, HTC derived AC or by salt templating of biomass materials. These raw biomass materials are first carbonized below $800{ }^{\circ} \mathrm{C}$ and are activated at 
950- $1000^{\circ} \mathrm{C}$ [80]. Otherwise, chemical activation of biomass material through the strong base, acid or salt prior could be carbonized at a lower temperature $400-700{ }^{\circ} \mathrm{C}$ [101].

$\mathrm{AC}$ was used first time as an electrode material for capacitive deionization in 1960's $[1,102]$. Though, AC has been used as an adsorbent for water treatment before the CDI was introduced. AC is considered at the top for electrochemical electrodes because of its unique electrical and thermal properties, low density, corrosion resistant, low elasticity, have a low coefficient of thermal expansion, good conductance, cost-efficient and availability in large quantities with purity [103]. Because of these properties, AC has a high surface area and porous structure. However, pore sizes of $\mathrm{AC}$ are divided into three parts such as, microporous, mesoporous and macroporous which have a diameter range of $2 \mathrm{~nm}, 2-50 \mathrm{~nm}$ and greater than $50 \mathrm{~nm}$ range, respectively. Materials can be synthesized with different surface areas, pore sizes, pore structures by considering different synthetic routes. Usually, the fabrication of CDI electrodes is achieved by certain ratios of carbon material, binders and conductive additives. Choi et al. [104] fabricated activated carbon powder with poly(viniylidenefuoride)-di-methylacetamid (ACP-PVDF-DMAc) polymer material that possessed $0.47 \quad \mathrm{~F} / \mathrm{cm}^{2}$ and $77.8 \%$ electrosorption capacity. Suresh et al. [105] introduced a new procedure to produce mesoporous conductive carbon blacks (MCCB), and composites of activated carbon with $75 \%$ salt adsorption capability. Anderson et al. [106] developed three-dimensional 3D composites via AC coating with a higher surface area on highly electrically conductive graphite felt activated carbon (GF-AC). A CDI system with 9 -cell $\left(300 \mathrm{~cm}^{2}\right)$ could obtain SAR of $8.7 \mathrm{mg} / \mathrm{g}$.
Additional research studies on metaloxide coating effects, carbon material and the applied current on the ions desorption in CDI process, suggest more assistance to select carbon materials and process parameters [107]. They utilized three different metal oxide sols; including acidic $\mathrm{SO}_{2}$, basic $\mathrm{SO}_{2}$ and $\gamma-\mathrm{AlO}_{2} \mathrm{H}$ to impregnate low surface carbon fibers sheets. However, obtained outcomes exhibited higher surface area of composite by immersing uncoated carbon fiber sheet with one of the three sols [108]. In recent times, antifouling coating substance (sulfobetaine methacrylate) was treated on porous carbon electrode by surface-initiated atom transfer radical polymerization (SIATRP) and the prepared electrode termed as PC-SBMA [109]. An adsorption capacity of PC-SMBA electrode in $\mathrm{NaCl}$ solution was achieved $16.5 \mathrm{mg} / \mathrm{g}$ in $245 \mathrm{mg} / \mathrm{L}$. They found that, after 1000 cycles at $2.5 \mathrm{~A} / \mathrm{g}$ constant current density, PC-SBMA-24 possessed 97.5 $\%$ capacitance retention, this exceptional stability is encouraging for long-term usage in the practical process. Though, there were few disadvantages, for instance, the weak binding strength of ions, low electrical capacitance, and high resistance of normally $\mathrm{AC}$ electrodes. The corresponding alteration strategies involve: altered pore structure and combined oxygenated functional groups in $\mathrm{H}_{2}$, $\mathrm{CO}_{2}, \mathrm{~N}_{2}, \mathrm{Ar}_{2}$ gasses [110,111], to enhance the hydrophilicity of materials, derived activated carbon materials from Al-based metal-organic gels $[112,113]$. Materials are calcined to acquire thermally stable, large surface area and appropriate pore structure. Another porous material; Carbide derived carbon (CDC) has a suitable and modifiable 0.5-2.2 $\mathrm{nm}$ pore size in the sub-nano range and is imprinted through chlorine [41, 114]. Porda et al. [115], developed CDCs electrodes from three dissimilar synthesis procedures such as, ordered mesoporous silicon carbide (OM-SiC$\mathrm{CDC}$ ), titanium carbide (TiC-CDC) and Hipe (High internal phase emulsion) SiC-CDC, and 
also compared properties of these electrodes. OM-SiC-CDC possessed the highest adsorption capacity at an applied potential of $1.2 \mathrm{~V}$.

CDI carbon electrode modification has been acquired from different research works, for instance. Lee et al. [56, 116] studied the effect of system operation parameters, Chang et al. [117] synthesized AC electrodes by a novel liquid binder, and Choi et al. [104, 118] investigated about controlling the electrode faradic reaction via using a binder. Avraham et al. [42, 119] studied the limitations of AC electrode charge efficiency in CDI operation, where single, double and surface oxidized AC electrode electrosorption mechanisms were investigated. However, it is possible to increase the charge efficiency through discharge potential, i.e., regeneration potential is higher than zero. If an $\mathrm{AC}$ electrode has a pore size less than $0.58 \mathrm{~nm}$, the $\mathrm{Cl}^{-}$ions cannot pass through the electrode and $\mathrm{AC}$ of pore size greater than $0.58 \mathrm{~nm}$, the oxygenated functional groups may have no apparent effect in the electrosorption process.

New approaches are introduced by modifying the AC electrode for desalination performance. An ion-selective membrane deposited CDI electrode [120], water soluble binder for AC electrode preparation [47] and doping of AC materials with other substances to enhance the capacity and pore structure. A combination of $\mathrm{AC}$ with other materials such as ion exchange resin, graphene [121], titania [35], and $\mathrm{MnO}_{2}$ [122] have been used for improved capacitance and the salt removal efficiency of AC material. An ion-exchange resin has enhanced electrode hydrophilicity and in addition to this increased the desalination capacity and ion-exchange resin deposited AC has achieved 35\% more charged species removal compared to one without ionexchange resin. Graphene/AC electrode materials exhibit amended ion capacity because graphene sheets serve as spacers which prohibit the $\mathrm{AC}$ accumulation results in high surface area availability. The electrical double layer formation rate was improved significantly in titania-containing AC electrode and ion removal efficiency was enhanced to $62.7 \%$ with good stability of the electrode. The mixture of $\mathrm{MnO}_{2} / \mathrm{AC}$ electrode material has appropriate pore size distribution, effective cation intercalation mechanism, along with double desalination quantity compared to AC electrode.

\section{Activated carbon cloth}

Activated carbon cloth (ACC) is one of the several forms of carbon which is extracted from natural biomass substances, for instance, coal [123], wood [103], starch [95] and coconut shells [103]. ACC has a high surface area $\left(1000-1980 \mathrm{~m}^{2} / \mathrm{g}\right)$ and is cost efficient [124]. Hence, ACC material has been well considered for CDI electrodes [125].

ACC, as a commercially accessible electrode material, possesses suitable characteristics; good conductance, mechanical stability, shape adjustability, good porosity [126]. Pure ACC electrodes have been utilized in numerous fields [127-129]. Recently, a facile method of producing particles on substrates surface has invited attention to enhance the electrosorption capacity and improve the energy efficiency of CDI electrodes. For instance, Lu Guo et al. [130], investigated the $\mathrm{Li}_{4} \mathrm{Ti}_{5} \mathrm{O}_{12}$ nanoflake array development on ACC material by simple immersion procedure. The $\mathrm{Li}_{4} \mathrm{Ti}_{5} \mathrm{O}_{12}$ modified electrode acquired a 300\% improvement in deionization capability from $7 \mathrm{mg} / \mathrm{g}$ to 25 $\mathrm{mg} / \mathrm{g}$, owing to its Faradic influences. Consequently, $83 \%$ charge efficiency enhancement and power consumption charged particles were reduced to $9.92 \times 10^{-20} \mathrm{~J} / \mathrm{mol}$, and the electrode. 
More recently, another related procedure was developed to grow nanopatterned Metal-Organic Framework (npMOF) of ZIF-67 nanocrystals on the ACC surface to achieve binder free modified carbon electrode [131]. The assembled MCDI performance was studied in various salt concentrations $(5-40 \mathrm{mM})$, including different salts such as $\mathrm{NaCl}, \mathrm{KCl}, \mathrm{MgCl}_{2}$, and $\mathrm{CaCl}_{2}$. These CDI electrodes exhibited $21.3 \mathrm{mg} / \mathrm{g}$ and $0.9 \mathrm{mg} / \mathrm{g}$ min maximum salt removal efficiency and desalination rate, respectively. This may attribute to the improved porosity and npMOF electrical impedance and electrodes exhibited high stability for nearly 30 cycles. Ryoo et al. [132, 133] studied the electrosorption outcomes of ACC and modified electrode of ACC with titania, silicon, zirconium and aluminum to improve the desalination performance of CDI technology. However, it was seen that titania was spread over the ACC surface, which caused reduced polar groups and physical adsorption reduction. While titania-ACC salt removal ability was improved due to adsorption sites and this modification of titania incorporated ACC electrode cause rapid desorption and good reversibility. Oh et al. [134] investigated an ACC chemical activation effect on electrosorption performance, and Myint et al. [135] worked on nano/micro sized $\mathrm{ZnO}$-ACC electrode for desalination process and these composite electrodes exhibited $22 \%$ salt removal competence compared to only ACC electrode for CDI performance. Hence, modifying ACC with other materials enhances the desalination performance of CDI technology.

\section{Carbon nanotube}

Carbon nanotube (CNT) is a novel material that possesses distinctive structure and extraordinary capacitance properties. CNTs are used in various areas, for instance, the energy storage device [136], aerospace
[137], medical [138] and also water treatment technology [136, 139]. CNT, which has been successfully introduced in the last decade, has gain greater interest as an electrode material and is widely used and is effective for the ionic species removal process. The electrosorption capacity of the CNT electrode has shown an efficient influence on $\mathrm{NaCl}$ solution [140]. This water desalination capacity of CNT is because of its distinctive properties such as, electrical conductivity, thermal stability and high aspect ratio. Santos et al. [141], presented a CDI electrode without the utilization of current collector sheet entail of unlike metal oxides combined into porous carbon nanotube fibers (CNTf). The altered electrodes; $\gamma-\mathrm{Al}_{2} \mathrm{O}_{3} / \mathrm{CNTf}$ as an anode and $\mathrm{SiO}_{2} / \mathrm{CNTf}$ as a cathode, acquired good electrical conductivity and low internal hindrance, showed $6.5 \mathrm{mg} / \mathrm{g}$ desalination capacity and $0.21 \mathrm{mg} / \mathrm{g}$ min average SAC with low power expenditure of $0.26 \mathrm{Wh} / \mathrm{g}$ and charge efficiency in brackish water was obtained $86 \%$. Electrodes were fabricated by continuous metal oxides colloidal dispersion spraying over CNTf, rolled from the deposition of chemical vapor reaction. In a more recent study, the atomic layer deposition (ALD) process was utilized to accumulate $\mathrm{TiO}_{2}$ nanoparticles onto the layer of the acidic functionalized multiwalled CNT membrane. Jianhua Feng et al. fabricated electrodes through this strategy for numerous applications and obtained $5.09 \mathrm{mg} / \mathrm{g}$ desalination efficiency in $40 \mathrm{mg} / \mathrm{L}$ initial $\mathrm{NaCl}$ solution [142].

Moreover, various research investigations have been attained by Heena et al. [139], who synthesized CNT electrodes for CDI system by making CNTs with 2 to 3 graphitic layers, and Chung et al. [143] studied the pristine based CNT (p-CNT), the authors mixed p-CNTs with $\mathrm{HNO}_{3}$ and $\mathrm{H}_{2} \mathrm{SO}_{4}$ $(1: 3)$ at $95{ }^{\circ} \mathrm{C}$ for $1 \mathrm{~h}$, this alteration increased the electrical conductivity of acid-treated 
CNTs (a-CNTs). The surface of a-CNTs was treated with oxygenated functional groups and it has increased the active sites availability which facilitates adsorption and enhanced the CNTs surface for ions removal ability [144]. However, compared with p-CNTs, the a-CNTs have achieved better CDI performance on higher capacity and efficiency for removing ions. The CNTs have some limitations due to which their salt removal capacity is limited such as the hydrophobic nature of CNTs decrease the surface interaction and have strong van der Waals forces [145]. So, there is a need to work further on oxygenated functional groups to enhance the pure CNTs dispensability. In 2017, a facile method was developed for the fabrication of electrodes with CNT thread. The prepared electrodes possessed a superior deionization capability of $139 \mathrm{mg} / \mathrm{g}$ and $2.78 \mathrm{mg} / \mathrm{g} \mathrm{min}$ average SAC with high charge efficiency $(80 \%)$. Besides, the electrosorption experiment was conducted with different anions $\left(\mathrm{Cl}^{-}, \mathrm{SO}_{4}{ }^{2-}\right.$ and $\left.\mathrm{NO}^{3-}\right)$ and cations $\left(\mathrm{Na}^{+}, \mathrm{K}^{+}, \mathrm{Mg}^{2+}\right.$ and $\mathrm{Ca}^{2+}$ ) [146]. Further, the activated carbon (AC) and CNTs were combined to get modified AC-CNTs. Shi et al. [147] and Lu et al. [148] worked on AC-CNTs composite. Shi et al. [147] produced CNTs-AC composite electrode. In their study, different proportions of CNTs were used with AC in addition to phenolic resin as a binder and the material was carbonized at $600{ }^{\circ} \mathrm{C}$ in an inert atmosphere $\left(\mathrm{N}_{2}\right.$ gas). It was observed that the prepared CNTs electrode with 10 wt $\%$ showed distinctive salt removal performance with more than $90 \%$ adsorption capacity. While, $\mathrm{Lu}$ et al. [148] worked on the fabrication of CNTs-AC composite by the simple method to acquire highly conductive material and this dual composite electrode was applicable for desalination.

\section{Carbon Nanotube and Graphene composite}

The CNTs and graphene composite
materials have shown extraordinary conductance and unique morphology. Graphene is one-layered graphite where carbon atoms are arranged in a hexagonal pattern. Carbon atoms in graphene are $\mathrm{sp}^{2}$ hybridized with $0.144 \mathrm{~nm}$ bond length and have a two-dimensional geometry. It has an electron mobility of $200,000 \mathrm{~cm}^{2} \mathrm{~V}^{-} \mathrm{s}^{-}$[149], which exhibits an excellent electrical conductivity of graphene. Graphene has a high surface area of $2630 \mathrm{~m}^{2} / \mathrm{g}$ [150] and due to the graphene sheet's interlayered open structure, it has good electrosorption performance. The adsorption and desorption behavior of single and double walled carbon nanotubes combined with graphene are recommended for CDI electrodes. The graphene sheet rolled in a cylinder-shaped is known as single-walled CNT (SWCNT). While, double-walled carbon nanotube (DWCNT) is two layers of graphene sheets forms a tube structure and multi-walled carbon nanotube are made of more than two graphene layers. The metallic and semiconducting properties of CNT depends on the carbon hexagon rings along the tubular surface. As electrode materials, CNT and graphene are considered much favorable because of good conductance, high surface area and uniform structure.

Hence, higher conductance and larger surface area of electrode cause more ions adsorption and store the ionic species in EDL on the electrode surface $[151,152]$. The conductive material is not only capable of higher adsorption capacity but also the rate of electrosorption which depends on the conductance ability of the material. Higher the electrical conductance faster will be the speeds of adsorption and desorption. Pan et al. [153] explored the comparative study of SWCNT and DWCNT with graphene-based electrodes and the experimental outcomes showed that the ion capacity of SWCNT and DWCNT were higher than pure graphene electrodes. They also worked on the effects of ions charges, size and quantity of ions 
electrosorption. Herein, it was found that anions were electrosorbed more efficiently and the capacity pattern of adsorbed ions observed for smaller ions were easier contact with the electrode, namely $\mathrm{Cl}^{-}>\mathrm{NO}_{3}->\mathrm{SO}_{4}{ }^{2-}$. Dai et al. [147, 154] produced a multi-walled carbon nanotube (MWCNT) electrode for $\mathrm{NaCl}$ adsorption and obtained a good ion capacity outcome in the CDI system. Zhang et al. [155] investigated the diameter effect of CNT as an electrode for the CDI technology, where the decrease in CNT diameter desalination performance was enhanced. Wang et al. [128] fabricated a 3-D carbon nanotube sponge through chemical vapor deposition and the prepared carbon nanotube sponge electrodes were applied for electrosorption. The ion removal capacity of the CNT sponge was observed higher than the carbon aerogel, AC-fiber and AC. Carbon nanotube composite with other distinctive materials such as, graphene [77, 156], mesoporous carbon $[157,158]$ and polyacrylic acid [159] were prepared for CDI performance. The graphene-carbon nanotube (G-CNT) composite was more efficient to electrosorption capacity than the components individually. It was observed that long CNTs connect together with graphene sheets and also inhibit the accumulation of individual layer i.e. enhance the composite electrical conductivity and deliver more surface respectively. Graphene is a novel material; it has shown competent adsorption capacity of CDI system than activated carbon even with a low specific surface area. Li et al. [40, 65, 160] synthesized graphene through the modified hummers method in $\mathrm{NaCl}$ solution and later applied it to the electrosorption of ferric ion through prepared graphene electrode.

Wang et al. [161, 162] worked on resol functionalized graphene, the graphene aggregation was inhibited by resol functionalization, which enhances the adsorption capacity. Jia et al. [163] developed a multi-step procedure for reduction of graphene oxide (GO), iron powder, sulphonic acid and hydrazine were used to slightly reduce GO then this mildly reduced GO was introduced with sulphonic functional groups to acquire good dispersion properties and finally, the functionalized GO was reduced by hydrazine. The synthesized material electrode revealed high adsorption capacity and regeneration performance. Lei et al. [164] worked on a novel iron-catalyzed carbonization method to prepare graphene nanosheets from glucose as a carbon source. 3-D graphene structure has unique properties as using different templating methods. Zhang et al. and Wang et al. [77, 165] synthesized graphene and ordered mesoporous carbon (GOMC) composite by core shell and triblockcopolymer templating method and applied prepared electrodes for the CDI process. Wang et al. [166] developed a modified method of thermal reduction, they prepared graphene using pyridine as an intercalating agent and applied for electrosorption process. Whereas, mesoporous carbon-carbon nanotube (MC-CNT) composite as CDI electrode showed good ion adsorption capacity without consuming a large amount of energy. Polyacrylic acid-carbon nanotube (PA-CNT) composite electrodes exhibited higher adsorption capacity than pure CNT and these films revealed good regeneration capability.

\section{Carbon Aerogel}

Carbon aerogels (CA) are carbon skeletons with nanosize air filled foams. The synthesis process initiates by sol-gel polymerization of resorcinol (1,3-dihydroxy benzene) with formaldehyde. The resorcinolformaldehyde (RF) aerogel precursor is obtained from highly cross-linked transparent hydrogels synthesized using resorcinol and formaldehyde in polycondensation process, which is dried under supercritical conditions. 
Carbon aerogel is formed by pyrolyzing RF aerogel in an inert atmosphere at a temperature $\left(600-1200{ }^{\circ} \mathrm{C}\right)$. CA is a promising applicant for energy storage and CDI electrode material. Different compounds can be used as a precursor such as, phenolresorcinol formaldehyde, phenol-furfural, melamine-formaldehyde, polyvinyl chloride and polyureas [167, 168]. CA has an excellent surface area and good electrical conductivity and is efficient electrode material for CDI systems [169]. Different forms of CA can be acquired such as, films, powders and microsphere [170]. Santiago et al. [44] utilized innovative hierarchical CA monoliths as a flow-through electrode substance. CA pore structure possessed both high electrosorption capacity rate and low flow hindrance. Farmer et al. [168, 171-175] worked on CA electrodes for the desalination process. CA electrodes were capable candidates for removal of different salts such as, $\mathrm{NaCl}, \mathrm{NaNO}_{3}, \mathrm{Na}_{2} \mathrm{SO}_{4}$, $\mathrm{Na}_{3} \mathrm{PO}_{4}, \mathrm{NH}_{4} \mathrm{ClO}_{4}$ and hexavalent chromium. Though, CA monolithic sheets might be prepared by monitoring the morphology. Farmer and others prepared CA thin sheet electrodes for electrosorption process. The potential drop was avoided by electrolyte flow through anode and cathode electrodes as observed in flowing through cell packed layers so inhibit the electrode material leaching. Experimental outcomes showed that with electrosorption operation adsorption capacity was decreased but could be recovered by reversing the electrodes.

Kumar et al. [176] prepared mechanically stable modifiable porous CA monoliths with a large surface area using a single-step sol-gel procedure. CA-silicic acid etched electrodes possessed $10.54 \mathrm{mg} / \mathrm{g} \mathrm{SAC}$ at $1.2 \mathrm{~V}$ applied voltage. This composite electrode material showed a good pore morphology and a good salt removal efficiency. Yang et al. [177] prepared silicagel-treated CA electrodes, which enhanced the electrosorption capacity of electrodes up to $28 \%$ due to better wettability and improved stability. Cho et al. [178] worked on the CAsilica gel composite material for CDI system through the paste rolling process, these modified electrodes exhibited good wettability, mechanical stability and regenerability. Gabelich et al. [64] investigated the electrosorption behavior of ionic species, mass and radius on CA electrodes. The conducted study exhibited that monovalent ions having small hydrated radii were preferentially removed over multivalent charged particles in an aqueous solution and smaller surface area availability for electrosorption due to electrodes small pore size. CA electrode fouling reduced effective desalination performance which was affected by natural organic matter.

\section{Ordered mesoporous carbon}

Ordered mesoporous carbon (OMC) is a carbon material having well-arranged uniform pore size in the $2-50 \mathrm{~nm}$ range. The uniform pore structure OMCs are acquired through the hard-template method in which the binding of carbon material precursors to certain templates by 3D pore structure occurs, and after the carbonization, the templates are detached. However, the soft-template approach was introduced to overcome the silica etching process's expensive phases and time consumption, where the carbon precursors are in direct association with organic amphiphilic surfactant template or block copolymer template [179].

However, enhancing surface area of material sightlessly is unwise, a very small pore may cause a double layer overlap effect which is non-conductive to ions regeneration. Initially, in 2008, Zou et al. [28] recommended that mesoporous carbon performs a significant role in adsorption and charged particles transportation. Mesoporous 
carbon was synthesized through self-assembly of triblock copolymer along with hydrogen bonded chains by a phenolic resin, for instance, phloroglucinol or resorcinol in acidic conditions and then carbonization (sometimes chemical activation). Nadakatti et al. [105] worked on the modification of OMC by introducing mesoporous carbon black. The prepared electrode is shown $100 \%$ ions removal efficiency for CDI technology. Peng et al. [158] synthesized the OMC and CNT composite material, the optimized quantity of CNT was found $10 \mathrm{wt} \%$ which revealed higher adsorption capacity. The stability and regeneration of these composite were also improved. Likewise, MCs fabrication with a precursor of calcium citrate salts and for MCs regeneration, its calcium waste is regained. Original MCs and regained MCs possessed efficient adsorption capacity, such as 23.73 and $23.33 \mu \mathrm{mol} / \mathrm{g}$, respectively [180].

To picture the efficiency of materials, their efficiency parameters are listed in Table 2. Mesoporous carbons have shown the highest SAC values.

Table 2. CDI performance and surface properties of carbon electrode materials.

\begin{tabular}{|c|c|c|c|c|c|}
\hline Electrode & $\begin{array}{l}\text { Voltage } \\
\text { (V) }\end{array}$ & $\begin{array}{l}\text { Surface area } \\
\left(\mathrm{m}^{2} / \mathrm{g}\right)\end{array}$ & $\begin{array}{l}\text { SAC } \\
\mathrm{mg} / \mathrm{g}\end{array}$ & $\begin{array}{c}\text { Influent water conc. } \\
\mathrm{mg} / \mathrm{L}\end{array}$ & Reference \\
\hline N-PHCS & 1.4 & 512 & 12.95 & 500 & [181] \\
\hline NCPC-900 & 1.2 & 1257 & 11.98 & 100 & [182] \\
\hline NPCS & 1.2 & 1640.5 & 14.91 & 1000 & [93] \\
\hline NDC-Cs-900 & 1.2 & 2830 & 15.0 & $5 \mathrm{mM}$ & [95] \\
\hline $\mathrm{KOH} / \mathrm{AC}$ & 1.0 & 2105 & 9.72 & 29 & [71] \\
\hline $\mathrm{SB}-\mathrm{CO}_{2}-700$ & 1.2 & 764 & 11.4 & $10 \mathrm{mM}$ & [183] \\
\hline $\mathrm{S}-\mathrm{RGO} / \mathrm{ACF}$ & 1.2 & 649 & 9.2 & 300 & [182] \\
\hline PC-SBMA & 1.2 & - & 16.5 & 245 & [109] \\
\hline PC800 & 1.4 & 1587 & 25.16 & 500 & [112] \\
\hline 3D-NPC & 1.4 & 1481 & 21 & 500 & [184] \\
\hline N-HMCS/HGH & 1.4 & 337.7 & 17.8 & 500 & [185] \\
\hline $\mathrm{MnO} 2 / / \mathrm{AC}-\mathrm{QPVP}$ & 1.4 & 193 & 14.9 & 500 & [186] \\
\hline $\begin{array}{l}\text { Hierarchical porous carbon } \\
\text { derived from polyHIPE }\end{array}$ & 1.2 & 2189 & 21.3 & 500 & [187] \\
\hline h-PC-800 & 1.2 & 1911.9 & 83.0 & 1000 & [87] \\
\hline $\begin{array}{l}\text { Hierarchical porous carbon } \\
\text { derived from cattle bone }\end{array}$ & 1.2 & 2147.43 & 19.35 & 500 & [188] \\
\hline $\mathrm{AC}$ & 1.5 & - & 3.70 & 200 & [189] \\
\hline $\mathrm{AC}$ & 1.2 & 968 & 0.25 & 25 & [28] \\
\hline $\mathrm{AC}$ & 1.2 & 1153 & 9.72 & 500 & [190] \\
\hline CNTs & 1.2 & 153 & 9.35 & 1000 & [191] \\
\hline CNFs & 1.2 & - & 3.2 & 60 & [192] \\
\hline CNFs & 1.6 & $335-712$ & 4.6 & 95 & [125] \\
\hline HbioC & 1.6 & 85.84 & 31.87 & 1000 & [193] \\
\hline NAC30/AC & 1.2 & $1887 / 2421$ & 24.7 & $8 \mathrm{mM}$ & [194] \\
\hline $\mathrm{N}-\mathrm{AC}$ & 1.2 & N/A & 2.85 & 50 & [195] \\
\hline NC-800 & 1.2 & 798 & 8.52 & $1 \mathrm{mM}$ & [196] \\
\hline $\mathrm{WMAC} / \mathrm{MnFFe}_{2} \mathrm{O}_{4}$ & 1.2 & 483 & 29.7 & 250 & [197] \\
\hline AN-CFs & 1.2 & 905.3 & 12.32 & 500 & [198] \\
\hline
\end{tabular}


Modification of OMC and its composites with different dopants have shown better adsorption capacity. Zou et al. [28, 199, 200] experimented with the electrosorption performance of OMC electrodes and observed that $\mathrm{OMC}$ has more desalination capability than AC because of optimized pore structure. Though, the ordered uniform structure has a $4.0 \mathrm{~nm}$ peak diameter, which exhibited good adsorption and desorption ability of electrode and rapid regeneration. OMCs were modified with nickel salt to get nickel-based OMC (NiOMC) electrode material for CDI process. The Ni-OMC exhibited a smaller ordered mesoporous structure with a peak diameter of $3.7 \mathrm{~nm}$ shifted from $4.0 \mathrm{~nm}$, possessed high surface area and the modified OMC electrodes showed good electrosorption capability. A comparison study of OMC with carbon aerogel was conducted by Tsouris et al. [201] and they found that OMC demonstrated more efficient CDI performance. This enhanced performance was related to pore size order that delivered higher surface area availability to ionic species.

The sustainable future of CDI depends on the development of cost-effective mesoporous carbons with adequate wettability and excellent desalination performance. The materials may be investigated with MCDI mode or an alternate mechanism may be investigated to replace membranes. Cyclability should also be taken into account for CDI to compete with the RO.

\section{Conclusions and recommendations}

Capacitive deionization having carbon electrodes with or without membranes is an established technology and commercial systems are available from various vendors. Still, CDI needs to climb a lot to compete with existing technologies like reverse osmosis (RO). Comparative cost evaluation of CDI and RO suggest that electrode and membranes are the largest cost component and their lifespan should be $10^{5}$ cycles for 5 min cycle duration. Therefore, any electrode material that shows remarkable CDI performance in terms of SAR values should also be cost effective and should withstand with cyclic performance.

This literature review suggests that CDI cell architecture plays a crucial role to enhance deionization efficiency. Compared to conventional CDI cell; MCDI and flow through CDI exhibit improved desalination capacity. Various carbon electrode materials are used for deionization. Thus, in EDL capacitive materials, the deionization capability is enhanced significantly after utilizing the carbon aerogel and porous carbon electrode initially used in CDI process. Mesoporous carbon gives a higher surface area with efficient adsorption sites. Double layer overlap effect may be seen in very small micropores that do not contribute effectively in ion desorption. CNT electrodes show mesoporous reticular morphology, which is advantageous for salt removal. Moreover, the unique interlayer of graphene eases the rapid ionic species transfer. Graphene composite electrodes with synergistic effect exhibit good capacitance, cyclic steadiness and offer good electrosorption. More investigations in research studies must be carried out to modify the current carbon electrodes or produce novel electrode materials and synthesis routes for CDI system scale up.

\section{Conflict of interest}

The authors declare no conflict of interest at any level related to this work.

\section{References}

1. D. Caudle, J. Tucker, J. Cooper, B. Arnold and A. Papastamataki, United States Department of the Interior, (1966) 190. 
https://agris.fao.org/agris-

search/search.do?recordID=US2013000 72477

2. B. Jia and W. Zhang, Nanoscale Res., Lett., 11 (2016) 64.

https://doi.org/10.1186/s11671-0161284-1

3. Institute, Field Operation of a 20 Gallons Per Day Pilot Plant Unit for Electrochemical Desalination of Brackish Water, (U.S. Department of the Interior, 1968.

https://books.google.com.pk/books?id= NSOct2-oIGsC

4. A. M. Johnson and J. Newman, $J$. Electrochem. Soc., 118 (1971) 510.

https://doi.org/10.1149/1.2408094

5. Andelman, M.D. and G.S. Walker, Charge barrier flow-through capacitor, 2004, Google Patents.

https://patents.google.com/patent/US670 9560B2/en

6. Y. M. Volfkovich, Russ. J. Electrochem., 56 (2020) 18.

https://doi.org/10.1134/s1023193520010097

7. X. Zhang, K. Zuo, X. Zhang, C. Zhang and P. Liang, Environmental Science: Water Res. Technol., 6 (2020) 243. https://doi.org/10.1039/c9ew00835g

8. X. Zhao, H. Wei, H. Zhao, Y. Wang and N. Tang, J. Electroanal. Chem., 873 (2020) 114416.

https://doi.org/10.1016/j.jelechem.2020. 114416

9. A. Kalfa, B. Shapira, A. Shopin, I. Cohen, E. Avraham and D. Aurbach, Chemosphere, 241 (2020) 125003.

https://doi.org/10.1016/j.chemosphere.20 $\underline{19.125003}$

10. A. Al-Karaghouli and L. L. Kazmerski, Renew. Sustain. Energy Rev., 24 (2013) 343.

https://doi.org/10.1016/j.rser.2012.12.064

11. P. G. Youssef, R. K. Al-Dadah and S. M. Mahmoud, Energy Procedia, 61 (2014) 2604.

https://doi.org/10.1016/j.egypro.2014.12.258
12. J. Elisadiki, T. E. Kibona, R. L. Machunda, M. W. Saleem, W.-S. Kim and Y. A. C. Jande, Biomass Convers. Biorefin, $10 \quad$ (2020) 1327. https://doi.org/10.1007/s13399-01900463-9

13. D. M. Warsinger, J. Swaminathan, E. Guillen-Burrieza, H. A. Arafat and J. H. Lienhard V, Desalination, 356 (2015) 294.

https://doi.org/10.1016/j.desal.2014.06.031

14. K. C. Ng, K. Thu, S. J. Oh, L. Ang, M. W. Shahzad and A. B. Ismail, Desalination, $356 \quad$ (2015) 255. https://doi.org/10.1016/j.desal.2014.10.025

15. M. Khayet and T. Matsuura, Membrane Distillation: Principles and Applications, (Elsevier Science, 2011.

https://books.google.com.pk/books?id=5 yzHdm8vOqMC

16. L. F. Greenlee, D. F. Lawler, B. D. Freeman, B. Marrot and P. Moulin, Water Res., $43 \quad$ (2009) 2317. https://doi.org/10.1016/j.watres.2009.03. $\underline{010}$

17. O. N. Demirer, R. M. Naylor, C. A. Rios Perez, E. Wilkes and C. Hidrovo, Desalination, $314 \quad$ (2013) 130. https://doi.org/10.1016/j.desal.2013.;01.014

18. M. Al-Shammiri and M. Safar, Desalination, $126 \quad$ (1999) 45. https://doi.org/10.1016/S00119164(99)00154-X

19. S. A. Abdul-Wahab and J. Abdo, Appl. Therm. Eng., 27 (2007) 413. https://doi.org/10.1016/j.applthermaleng. 2006.07.010

20. O. A. Hamed, M. A. K. Al-Sofi, M. Imam, G. M. Mustafa, K. Ba Mardouf and H. Al-Washmi, Desalination, 128 (2000) 281.

https://doi.org/10.1016/S00119164(00)00043-6

21. F. Al-Juwayhel, H. El-Dessouky and H. Ettouney, Desalination, 114 (1997) 253. https://doi.org/10.1016/S00119164(98)00017-4 
22. R. Bahar, M. N. A. Hawlader and L. S. Woei, Desalination, 166 (2004) 123. https://doi.org/10.1016/j.desal.2004.06.066

23. C. Fritzmann, J. Löwenberg, T. Wintgens and T. Melin, Desalination, 216 (2007) 1.

https://doi.org/10.1016/j.desal.2006.12.0 $\underline{09}$

24. J. Kaschemekat, W. Hilgendorff, Bo, x030B, K. W. ddeker, A. M. Hassan and A. L. A. Malik, Desalination, 46 (1983) 151.

https://doi.org/10.1016/0011-

9164(83)87148-3

25. J.-G. Lee and W.-S. Kim, Desalination, 331 (2013) 46.

https://doi.org/10.1016/j.desal.2013.10.0 $\underline{22}$

26. M. I. Ali, E. K. Summers, H. A. Arafat and J. H. L. V, Desalination, 306 (2012) 60.

https://doi.org/10.1016/j.desal.2012.07.0 $\underline{43}$

27. Y. A. C. Jande and W. S. Kim, Desalination, $329 \quad$ (2013) 29. https://doi.org/10.1016/j.desal.2013.08.0 $\underline{23}$

28. L. Zou, L. Li, H. Song and G. Morris, Water Res., $42 \quad$ (2008) 2340. https://doi.org/10.1016/j.watres.2007.12. $\underline{022}$

29. J. O. M. Bockris, A. K. N. Reddy and M. E. Gamboa-Aldeco, Modern Electrochemistry 2B: Electrodics in Chemistry, Engineering, Biology and Environmental Science, (Plenum Press, 1998.

https://books.google.com.pk/books?id= V3tpJrG1H5wC

30. J. Lee, S. Kim, C. Kim and J. Yoon, Energy Environ. Sci., 7 (2014) 3683. https://doi.org/10.1039/c4ee02378a

31. P. Srimuk, J. Lee, S. Fleischmann, S. Choudhury, N. Jäckel, M. Zeiger, C. Kim, M. Aslan and V. Presser, J. Mater. Chem. A, 5 (2017) 15640. https://doi.org/10.1039/c 7ta03120c
32. S. Porada, A. Shrivastava, P. Bukowska, P. M. Biesheuvel and K. C. Smith, Electrochim. Acta, 255 (2017) 369.

https://doi.org/10.1016/j.electacta.2017.0 9.137

33. P. Srimuk, F. Kaasik, B. Krüner, A. Tolosa, S. Fleischmann, N. Jäckel, M. C. Tekeli, M. Aslan, M. E. Suss and V. Presser, J. Mater. Chem. A, 4 (2016) 18265. https://doi.org/10.1039/c6ta07833h

34. F. Xing, T. Li, J. Li, H. Zhu, N. Wang and X. Cao, Nano Energy, 31 (2017) 590.

https://doi.org/10.1016/j.nanoen.2016.12 .012

35. J.-Y. Lee, S.-J. Seo, S.-H. Yun and S.-H. Moon, Water Res., 45 (2011) 5375. https://doi.org/10.1016/j.watres.2011.06. $\underline{028}$

36. M. E. Suss, S. Porada, X. Sun, P. M. Biesheuvel, J. Yoon and V. Presser, Energy Environ. Sci., 8 (2015) 2296. https://doi.org/10.1039/c5ee00519a

37. P. Liu, H. Wang, T. Yan, J. Zhang, L. Shi and D. Zhang, J. Mater. Chem. A, 4 (2016) 5303.

https://doi.org/10.1039/c5ta10680j

38. Y. Bouhadana, E. Avraham, A. Soffer and D. Aurbach, AIChE J., 56 (2010) 779.

https://doi.org/10.1002/aic.12005

39. P. Xu, J. E. Drewes, D. Heil and G. Wang, Water Res., 42 (2008) 2605. https://doi.org/10.1016/j.watres.2008.01. 011

40. H. Li, L. Zou, L. Pan and Z. Sun, Environ. Sci. Technol., 44 (2010) 8692. https://doi.org/10.1021/es101888j

41. S. Porada, L. Weinstein, R. Dash, A. van der Wal, M. Bryjak, Y. Gogotsi and P. M. Biesheuvel, ACS Appl. Mater. Interf, 4 (2012) 1194. https://doi.org/10.1021/am201683j 
42. E. Avraham, Y. Bouhadana, A. Soffer and D. Aurbach, J. Electrochem. Soc., 156 (2009) P95. https://doi.org/10.1149/1.3115463

43. I. Cohen, E. Avraham, M. Noked, A. Soffer and D. Aurbach, J. Phys. Chem. C, 115 (2011) 19856. https://doi.org/10.1021/jp206956a

44. M. E. Suss, T. F. Baumann, W. L. Bourcier, C. M. Spadaccini, K. A. Rose, J. G. Santiago and M. Stadermann, Energy Environ. Sci., 5 (2012) 9511. https://doi.org/10.1039/c2ee21498a

45. M. E. Suss, P. M. Biesheuvel, T. F. Baumann, M. Stadermann and J. G. Santiago, Environ. Sci. Technol., 48 (2014) 2008. https://doi.org/10.1021/es403682n

46. S. Porada, R. Zhao, A. van der Wal, V. Presser and P. M. Biesheuvel, Prog. Mater. Sci., $58 \quad$ (2013) 1388. https://doi.org/10.1016/j.pmatsci.2013.0 3.005

47. B.-H. Park and J.-H. Choi, Electrochim. Acta, 55 (2010) 2888.

https://doi.org/10.1016/j.electacta.2009.1 2.084

48. P. M. Biesheuvel, R. Zhao, S. Porada and A. van der Wal, J. Colloid Interf Sci., 360 (2011) 239. https://doi.org/10.1016/j.jcis.2011.04.04 $\underline{9}$

49. Y.-J. Kim and J.-H. Choi, Water Res., 46 (2012) 6033.

https://doi.org/10.1016/j.watres.2012.08. 031

50. M. Duduta, B. Ho, V. C. Wood, P. Limthongkul, V. E. Brunini, W. C. Carter and Y.-M. Chiang, Adv. Energy Mater., 1 (2011) 511. https://doi.org/10.1002/aenm.201100152

51. V. E. Brunini, Y.-M. Chiang and W. C. Carter, Electrochim. Acta, 69 (2012) 301.

https://doi.org/10.1016/j.electacta.2012.0 $\underline{3.006}$
52. V. Presser, C. R. Dennison, J. Campos, K. W. Knehr, E. C. Kumbur and Y. Gogotsi, Adv. Energy Mater., 2 (2012) 895.

https://doi.org/10.1002/aenm.201100768

53. K. B. Hatzell, E. Iwama, A. Ferris, B. Daffos, K. Urita, T. Tzedakis, F. Chauvet, P.-L. Taberna, Y. Gogotsi and P. Simon, Electrochem. Comm., 43 (2014) 18.

https://doi.org/10.1016/j.elecom.2014.03 .003

54. A. S. Yasin, M. Obaid, Ibrahim M. A. Mohamed, A. Yousef and N. A. M. Barakat, RSC Adv., 7 (2017) 4616. https://doi.org/10.1039/c6ra26039j

55. I. Cohen, E. Avraham, Y. Bouhadana, A. Soffer and D. Aurbach, Electrochim. Acta, 106 (2013) 91.

https://doi.org/10.1016/j.electacta.2013.0 5.029

56. J.-H. Lee, W.-S. Bae and J.-H. Choi, Desalination, $258 \quad$ (2010) 159. https://doi.org/10.1016/j.desal.2010.03.0 $\underline{20}$

57. D. He, C. E. Wong, W. Tang, P. Kovalsky and T. D. Waite, Environ. Sci. Technol. Lett., 3 (2016) 222. https://doi.org/10.1021/acs.estlett.6b001 $\underline{24}$

58. X. Gao, J. Landon, J. K. Neathery and K. Liu, J. Electrochem. Soc., 160 (2013) E106.

https://doi.org/10.1149/2.111309jes

59. X. Gao, A. Omosebi, J. Landon and K. Liu, Energy Environ. Sci., 8 (2015) 897. https://doi.org/10.1039/c4ee03172e

60. S. Vafakhah, Z. Beiramzadeh, M. Saeedikhani and H. Y. Yang, Desalination, $493 \quad$ (2020) 114662. https://doi.org/10.1016/j.desal.2020.114 $\underline{662}$

61. L. Zou, G. Morris and D. Qi, Desalination, 225 (2008) 329.

https://doi.org/10.1016/j.desal.2007.07.0 14 
62. A. G. El-Deen, N. A. M. Barakat, K. A. Khalil and H. Y. Kim, New J. Chem., 38 (2014) 198. https://doi.org/10.1039/c3nj00576c

63. L. Wang, M. Wang, Z.-H. Huang, T. Cui, X. Gui, F. Kang, K. Wang and D. Wu, J. Mater. Chem., 21 (2011) 18295. https://doi.org/10.1039/c 1 jm13105b

64. C. J. Gabelich, T. D. Tran and I. H. M. Suffet, Environ. Sci. Technol., 36 (2002) 3010. https://doi.org/10.1021/es0112745

65. H. Li, T. Lu, L. Pan, Y. Zhang and Z. Sun, J. Mater. Chem., 19 (2009) 6773. https://doi.org/10.1039/b907703k

66. Y. Chen, Y. Zhu, Z. Wang, Y. Li, L. Wang, L. Ding, X. Gao, Y. Ma and Y. Guo, Adv. Colloid Interf Sci., 163 (2011) 39.

https://doi.org/10.1016/j.cis.2011.01.006

67. J. J. Chew and V. Doshi, Renew. Sustain. Energy Rev., 15 (2011) 4212. https://doi.org/10.1016/j.rser.2011.09.01 7

68. E. Taer, R. Taslim, Z. Aini, S. D. Hartati and W. S. Mustika, AIP Conf Proc, 1801 (2017) 040004. https://doi.org/10.1063/1.4973093

69. G.-X. Li, P.-X. Hou, S.-Y. Zhao, C. Liu and H.-M. Cheng, Carbon, 101 (2016) 1. https://doi.org/10.1016/j.carbon.2015.12. $\underline{095}$

70. J. J. Lado, R. L. Zornitta, F. A. Calvi, M. I. Tejedor-Tejedor, M. A. Anderson and L. A. M. Ruotolo, J. Anal. Appl. Pyrol, 120 (2016) 389.

https://doi.org/10.1016/j.jaap.2016.06.00 $\underline{9}$

71. C.-L. Yeh, H.-C. Hsi, K.-C. Li and C.-H. Hou, Desalination, 367 (2015) 60. https://doi.org/10.1016/j.desal.2015.03.0 $\underline{35}$

72. P.-Z. Guo, Q.-Q. Ji, L.-L. Zhang, S.-Y. Zhao and X.-S. Zhao, Acta PhysicoChim. Sinica, 27 (2011) 2836. https://www.ingentaconnect.com/content /apcs/apcs/201 1/00000027/00000012/art 00019

73. G. Quan, L. Chu, X. Han, C. Ding, T. Chen and J. Yan, Water Sci. Technol., 74 (2016) 1821.

https://doi.org/10.2166/wst.2016.372

74. P. Wang, Q. Wang, G. Zhang, H. Jiao, X. Deng and L. Liu, J. Solid State Electrochem., $\quad 20 \quad$ (2016) 319. https://doi.org/10.1007/s10008-015$\underline{3042-1}$

75. T. E. Rufford, D. Hulicova-Jurcakova, Z. Zhu and G. Q. Lu, Electrochem. Comm., 10 (2008) 1594. https://doi.org/10.1016/j.elecom.2008.08 .022

76. T. Alfredy, Y. A. C. Jande and T. Pogrebnaya, J. Water Reuse Desal., 9 (2019) 282.

https://doi.org/10.2166/wrd.2019.074

77. D. Zhang, X. Wen, L. Shi, T. Yan and J. Zhang, Nanoscale, 4 (2012) 5440. 10.1039/c2nr31154b

78. M. P. Maniscalco, C. Corrado, R. Volpe and A. Messineo, Bioresour. Technol. Rep, 11 (2020) 100435. https://doi.org/10.1016/j.biteb.2020.1004 35

79. S. Manocha, L. M. Manocha, P. Joshi, B. Patel, G. Dangi and N. Verma, AIP Conf Proc, 1538 (2013) 120. https://doi.org/10.1063/1.4810041

80. R. C. Bansal and M. Goyal, Activated Carbon Adsorption, (CRC Press, 2005). https://books.google.com.pk/books?id= VUluBwAAQBAJ

81. T. S. Hui and M. A. A. Zaini, Carbon Lett., 16 (2015) 275. https://doi.org/10.5714/CL.2015.16.4.27 $\underline{5}$

82. M. Zong, Y. Zhang, K. Li, C. Lv, P. Tian, Y. Zhao and B. Liang, Electrochim. Acta, 329 (2020) 135089. https://doi.org/10.1016/j.electacta.2019.1 $\underline{35089}$ 
83. T. Wang, Y. Zhai, Y. Zhu, C. Li and G. Zeng, Renew. Sustain. Energy Rev., 90 (2018) 223.

https://doi.org/10.1016/j.rser.2018.03.07 $\underline{1}$

84. A. Jain, R. Balasubramanian and M. P. Srinivasan, Chem. Eng. J., 283 (2016) 789.

https://doi.org/10.1016/j.cej.2015.08.014

85. Z. Xie, X. Shang, J. Yan, T. Hussain, P. Nie and J. Liu, Electrochim. Acta, 290 (2018) 666.

https://doi.org/10.1016/j.electacta.2018.0 9.104

86. H. Wang, T. Yan, J. Shen, J. Zhang, L. Shi and D. Zhang, Environ. Sci.: Nano, 7 (2020) 317. https://doi.org/10.1039/c9en01233h

87. P. Zhang, J. Li and M. B. Chan-Park, ACS Sustain. Chem. Eng., 8 (2020) 9291.

https://doi.org/10.1021/acssuschemeng.0 c00515

88. S. K. Mohamed, M. Abuelhamd, N. K. Allam, A. Shahat, M. Ramadan and H. M. A. Hassan, Desalination, 477 (2020) 114278.

https://doi.org/10.1016/j.desal.2019.114 278

89. X. F. Zhang, B. Wang, J. Yu, X. N. Wu, Y. H. Zang, H. C. Gao, P. C. Su and S. Q. Hao, RSC Adv., 8 (2018) 1159. https://doi.org/10.1039/c7ra10689k

90. P. Liu, T. Yan, L. Shi, H. S. Park, X. Chen, Z. Zhao and D. Zhang, J. Mater. Chem. A, $5 \quad$ (2017) 13907. https://doi.org/10.1039/c7ta02653f

91. N. Fechler, T.-P. Fellinger and M. Antonietti, Adv. Mater., 25 (2013) 75. https://doi.org/10.1002/adma.201203422

92. X. Deng, B. Zhao, L. Zhu and Z. Shao, Carbon, 93 (2015) 48.

https://doi.org/10.1016/j.carbon.2015.05. $\underline{031}$

93. Y. Liu, X. Xu, M. Wang, T. Lu, Z. Sun and L. Pan, J. Mater. Chem. A, 3 (2015)
17304.

https://doi.org/10.1039/c5ta03663a

94. Y. Liu, T. Chen, T. Lu, Z. Sun, D. H. C. Chua and L. Pan, Electrochim. Acta, 158 (2015) 403.

https://doi.org/10.1016/j.electacta.2015.0 1.179

95. S. Porada, F. Schipper, M. Aslan, M. Antonietti, V. Presser and T.-P. Fellinger, (2015).

https://oar.tib.eu/jspui/handle/123456789 1234

96. S. Tian, J. Wu, X. Zhang, K. Ostrikov and Z. Zhang, Chem. Eng. J., 380 (2020) 122514. https://doi.org/10.1016/j.cej.2019.12251 $\underline{4}$

97. C. Zhao, G. Liu, N. Sun, X. Zhang, G. Wang, Y. Zhang, H. Zhang and H. Zhao, Chem. Eng. J., 334 (2018) 1270. https://doi.org/10.1016/j.cej.2017.11.069

98. S. F. Evans, M. R. Ivancevic, D. J. Wilson, Z. D. Hood, S. P. Adhikari, A. K. Naskar, C. Tsouris and M. P. Paranthaman, Desalination, 464 (2019) 25.

https://doi.org/10.1016/j.desal.2019.04.0 02

99. Z. U. Khan, T. Yan, L. Shi and D. Zhang, Environ. Sci.: Nano, 5 (2018) 980.

https://doi.org/10.1039/c7en01246b

100. A. Ban, A. Schafer and H. Wendt, J. Appl. Electrochem., 28 (1998) 227. https://doi.org/10.1023/a:100324722904 9

101. H. Teng, T.-S. Yeh and L.-Y. Hsu, Carbon, 36 (1998) 1387. https://doi.org/10.1016/S00086223(98)00127-4

102. Murphy, G. W. (1969). Activated carbon used as electrodes in electrochemical demineralization of saline water. https://agris.fao.org/agrissearch/search.do?recordID=US2013003 22064 
103. K. Zaid and A. Suriani, Sci. Int., 29 (2017) e289.

https://www.researchgate.net/profile/Kh ayri-Al-

Zalit/publication/1GV9Jm2u7rmsCe65w KzPTw5jtS38n2tVEGiERIGV9Jm2u 7r msCe65wKzPTw5jtS38n2tVEGiDtbLgj H2m5c8emE66pjdExmgep47BAdKTrCJ 7CATIONS/links/5a6843a9aca2720266 b6c264/A-REVIEW-ON-ELECTRODEMATERIALS-USED-INCAPACITIVE-DEIONIZATIONPROCESSES-FOR-WATERTREATMENT-APPLICATIONS.pdf

104. J.-H. Choi, Sep. Purif. Technol., 70 (2010) 362 .

https://doi.org/10.1016/j.seppur.2009.10. $\underline{023}$

105. S. Nadakatti, M. Tendulkar and $M$. Kadam, Desalination, 268 (2011) 182. https://doi.org/10.1016/j.desal.2010.10.0 $\underline{20}$

106. Y. Wang, I. Vázquez-Rodríguez, C. Santos, E. García-Quismondo, J. Palma, M. A. Anderson and J. J. Lado, Chem. Eng. J., 392 (2020) 123698.

https://doi.org/10.1016/j.cej.2019.12369 8

107. J. J. Wouters, M. I. Tejedor-Tejedor, J. J. Lado, R. Perez-Roa and M. A. Anderson, J. Electrochem. Soc., 165 (2018) E148.

https://doi.org/10.1149/2.0271805jes

108. J. J. Wouters, J. J. Lado, M. I. TejedorTejedor, R. Perez-Roa and M. A. Anderson, Electrochim. Acta, 112 (2013) 763.

https://doi.org/10.1016/j.electacta.2013.0 $\underline{8.170}$

109. P. Zhang, P. A. Fritz, K. Schroën, H. Duan, R. M. Boom and M. B. ChanPark, ACS Appl. Mater. Interf, 10 (2018) 33564. https://doi.org/10.1021/acsami.8b11708

110. M. Aslan, M. Zeiger, N. Jäckel, I. Grobelsek, D. Weingarth and V. Presser,
J. Condens. Matter Phys., 28 (2016) 114003.

https://doi.org/10.1088/09538984/28/11/114003

111. I. Villar, S. Roldan, V. Ruiz, M. Granda, C. Blanco, R. Menéndez and R. Santamaría, Energy Fuels, 24 (2010) 3329.

https://doi.org/10.1021/ef901453q

112. Z. Wang, T. Yan, G. Chen, L. Shi and D. Zhang, ACS Sustain. Chem. Eng., 5 (2017) 11637.

https://doi.org/10.1021/acssuschemeng.7 b03015

113. L. Li, S. Xiang, S. Cao, J. Zhang, G. Ouyang, L. Chen and C.-Y. Su, Nat. Comm., 4 (2013) 1774. https://doi.org/10.1038/ncomms2757

114. V. Presser, M. Heon and Y. Gogotsi, Adv. Funct. Mater., 21 (2011) 810. https://doi.org/10.1002/adfm.201002094

115. S. Porada, L. Borchardt, M. Oschatz, M. Bryjak, J. S. Atchison, K. J. Keesman, S. Kaskel, P. M. Biesheuvel and V. Presser, Energy Environ. Sci., 6 (2013) 3700. https://doi.org/10.1039/c3ee42209g

116. J.-B. Lee, K.-K. Park, S.-W. Yoon, P.-Y. Park, K.-I. Park and C.-W. Lee, Desalination, 237 (2009) 155. https://doi.org/10.1016/j.desal.2007.11.0 $\underline{58}$

117. L. Chang, Y. Yu, X. Duan and W. Liu, Sep. Sci. Technol., 48 (2012) 359. https://doi.org/10.1080/01496395.2012.6 75000

118. J.-A. Lim, N.-S. Park, J.-S. Park and J.H. Choi, Desalination, 238 (2009) 37. https://doi.org/10.1016/j.desal.2008.01.0 $\underline{33}$

119. E. Avraham, M. Noked, Y. Bouhadana, A. Soffer and D. Aurbach, Electrochim. Acta, 56 (2010) 441. https://doi.org/10.1016/j.electacta.2010.0 8.056

120. J.-S. Kim and J.-H. Choi, J. Membr. Sci., 355 (2010) 85. 
https://doi.org/10.1016/j.memsci.2010.0 3.010

121. H. Li, L. Pan, C. Nie, Y. Liu and Z. Sun, J. Mater. Chem., 22 (2012) 15556. https://doi.org/10.1039/c2jm32207b

122. J. Yang, L. Zou, H. Song and Z. Hao, Desalination, 276 (2011) 199.

https://doi.org/10.1016/j.desal.2011.03.0 $\underline{44}$

123. F. F. Prinsloo, D. P. J. Opperman, C. Budeli and D. Hauman, The production of activated carbon from high-ash subbituminous and bituminous South African coals, (Pittsburgh Coal Conference, Pittsburgh, PA (US); Sasol Technology Ltd, Sasolburg (ZA), (1999).

https://www.osti.gov/biblio/20082323

124. M. M. Alam, M. A. Hossain, M. D. Hossain, M. A. H. Johir, J. Hossen, M. S. Rahman, J. L. Zhou, A. T. M. K. Hasan, A. K. Karmakar and M. B. Ahmed, Processes, 8 (2020) 203. https://www.mdpi.com/22279717/8/2/203

125. G. Wang, C. Pan, L. Wang, Q. Dong, C. $\mathrm{Yu}, \mathrm{Z}$. Zhao and J. Qiu, Electrochim. Acta, 69 (2012) 65.

https://doi.org/10.1016/j.electacta.2012.0 2.066

126. H.-G. Wang, W. Li, D.-P. Liu, X.-L. Feng, J. Wang, X.-Y. Yang, X.-b. Zhang, Y. Zhu and Y. Zhang, Adv. Mater., 29 (2017) 1703012.

https://doi.org/10.1002/adma.201703012

127. C. Kim, P. Srimuk, J. Lee, S. Fleischmann, M. Aslan and V. Presser, Carbon, 122 (2017) 329.

https://doi.org/10.1016/j.carbon.2017.06. $\underline{077}$

128. Y. Bouhadana, E. Avraham, M. Noked, M. Ben-Tzion, A. Soffer and D. Aurbach, J. Phys. Chem. C, 115 (2011) 16567.

https://doi.org/10.1021/jp2047486
129. E. Avraham, M. Noked, A. Soffer and D. Aurbach, Electrochim. Acta, 56 (2011) 6312.

https://doi.org/10.1016/j.electacta.2011.0 $\underline{5.037}$

130. L. Guo, D. Kong, M. E. Pam, S. Huang, M. Ding, Y. Shang, C. Gu, Y. Huang and H. Y. Yang, J. Mater. Chem. A, 7 (2019) 8912.

https://doi.org/10.1039/c9ta00700h

131. Y. Zhang, L. Ji, Y. Zheng, H. Liu and X. Xu, Sep. Purif. Technol., 234 (2020) 116124. https://doi.org/10.1016/j.seppur.2019.11 6124

132. M.-W. Ryoo, J.-H. Kim and G. Seo, J. Colloid Interf Sci., 264 (2003) 414. https://doi.org/10.1016/S00219797(03)00375-8

133. M.-W. Ryoo and G. Seo, Water Res., 37 (2003) 1527.

https://doi.org/10.1016/S00431354(02)00531-6

134. H.-J. Oh, J.-H. Lee, H.-J. Ahn, Y. Jeong, Y.-J. Kim and C.-S. Chi, Thin Solid Films, 515 (2006) 220. https://doi.org/10.1016/j.tsf.2005.12.146

135. M. T. Z. Myint, S. H. Al-Harthi and J. Dutta, Desalination, 344 (2014) 236. https://doi.org/10.1016/j.desal.2014.03.0 $\underline{37}$

136. T. Chen and L. Dai, Mater. Today, 16 (2013) 272.

https://doi.org/10.1016/j.mattod.2013.07. $\underline{002}$

137. N. R. Council, D. E. P. Sciences, A. S. E. Board and S. C. N. T. Roadmaps, National Academies Press, (2012). https://books.google.com.pk/books?id=SFBDO6PKmUC

138. H. He, L. A. Pham-Huy, P. Dramou, D. Xiao, P. Zuo and C. Pham-Huy, Biomed Res. Int., (2013) 578290. https://doi.org/10.1155/2013/578290

139. Mutha, H.K., Carbon nanotube electrodes for capacitive deionization, 
Massachusetts Institute of Technology, (2013). http://hdl.handle.net/1721.1/85478

140. C. Nie, L. Pan, Y. Liu, H. Li, T. Chen, T. Lu and Z. Sun, Electrochim. Acta, 66 (2012) 106.

https://doi.org/10.1016/j.electacta.2012.0 1.064

141. C. Santos, J. J. Lado, E. GarcíaQuismondo, I. V. Rodríguez, D. Hospital-Benito, J. Palma, M. A. Anderson and J. J. Vilatela, J. Mater. Chem. A, 6 (2018) 10898. https://doi.org/10.1039/c8ta01128a

142. J. Feng, S. Xiong and Y. Wang, Sep. Purif. Technol., 213 (2019) 70. https://doi.org/10.1016/j.seppur.2018.12. $\underline{026}$

143. S. Chung, H. Kang, J. D. Ocon, J. K. Lee and J. Lee, Curr. Appl. Phys., 15 (2015) 1539.

https://doi.org/10.1016/j.cap.2015.09.004

144. A. H. Norzilah, A. Fakhru'l-Razi, T. S. Y. Choong and A. L. Chuah, $J$. Nanomater., $2011 \quad$ (2011) 495676. https://doi.org/10.1155/2011/495676

145. S. Yang, D. Shao, X. Wang and M. Nagatsu, RSC Adv., 4 (2014) 4856. https://doi.org/10.1039/c3ra46701e

146. M. Moronshing and C. Subramaniam, ACS Appl. Mater. Interf, 9 (2017) 39907. https://doi.org/10.1021/acsami.7b11866

147. K. Dai, L. Shi, D. Zhang and J. Fang, Chem. Eng. Sci., 61 (2006) 428. https://doi.org/10.1016/j.ces.2005.07.030

148. W. Lu, R. Hartman, L. Qu and L. Dai, J. Phys. Chem. Lett., 2 (2011) 655. https://doi.org/10.1021/jz200104n

149. Choi, W., \& Lee, J.-W. (Eds.). (2011). (1st ed.). CRC Press. https://doi.org/10.1201/b1 1259

150. A. Peigney, C. Laurent, E. Flahaut, R. R. Bacsa and A. Rousset, Carbon, 39 (2001) 507. https://doi.org/10.1016/S00086223(00)00155-X
151. K. Y. Foo and B. H. Hameed, J. Hazard. Mater., 170 (2009) 552. https://doi.org/10.1016/j.jhazmat.2009.0 5.057

152. Y. Oren, Desalination, 228 (2008) 10. https://doi.org/10.1016/j.desal.2007.08.005

153. H. Li, L. Pan, T. Lu, Y. Zhan, C. Nie and Z. Sun, J. Electroanal. Chem., 653 (2011) 40. https://doi.org/10.1016/j.jelechem.2011. 01.012

154. K. Dai, L. Shi, J. Fang, D. Zhang and B. Yu, Mater. Lett., 59 (2005) 1989. https://doi.org/10.1016/j.matlet.2005.01. 042

155. Y. Gao, L. Pan, H. Li, Y. Zhang, Z. Zhang, Y. Chen and Z. Sun, Thin Solid Films, 517 (2009) 1616. https://doi.org/10.1016/j.tsf.2008.09.065

156. Z. Sui, Q. Meng, X. Zhang, R. Ma and B. Cao, J. Mater. Chem., 22 (2012) 8767. https://doi.org/10.1039/c2jm00055e

157. Z. Peng, D. Zhang, T. Yan, J. Zhang and L. Shi, Appl. Surf. Sci., 282 (2013) 965. https://doi.org/10.1016/j.apsusc.2013.06.107

158. Z. Peng, D. Zhang, L. Shi and T. Yan, $J$. Mater. Chem., 22 (2012) 6603. https://doi.org/10.1039/c2jm16735b

159. C. Nie, L. Pan, H. Li, T. Chen, T. Lu and Z. Sun, J. Electroanal. Chem., 666 (2012) 85.

https://doi.org/10.1016/j.jelechem.2011. $\underline{12.006}$

160. H. Li, L. Zou, L. Pan and Z. Sun, Sep. Purif. Technol., 75 (2010) 8.

https://doi.org/10.1016/j.seppur.2010.07. 003

161. Z. Wang, B. Dou, L. Zheng, G. Zhang, Z. Liu and Z. Hao, Desalination, 299 (2012) 96.

https://doi.org/10.1016/j.desal.2012.05.0 $\underline{28}$

162. Z. Wang, L. Yue, Z.-T. Liu, Z.-H. Liu and Z. Hao, J. Mater. Chem., 22 (2012) 14101. https://doi.org/10.1039/c2jm32175k 
163. B. Jia and L. Zou, Carbon, 50 (2012) 2315.

https://doi.org/10.1016/j.carbon.2012.01. 051

164. H. Lei, T. Yan, H. Wang, L. Shi, J. Zhang and D. Zhang, J. Mater. Chem. A, 3 (2015) 5934.

https://doi.org/10.1039/c4ta05713a

165. H. Wang, L. Shi, T. Yan, J. Zhang, Q. Zhong and D. Zhang, J. Mater. Chem. A, 2 (2014) 4739.

https://doi.org/10.1039/c3ta15152b

166. H. Wang, D. Zhang, T. Yan, X. Wen, L.

Shi and J. Zhang, J. Mater. Chem., 22 (2012) 23745.

https://doi.org/10.1039/c2jm35340g

167. R. W. Pekala, J. C. Farmer, C. T. Alviso,

T. D. Tran, S. T. Mayer, J. M. Miller and

B. Dunn, J. Non-Cryst. Solids, 225 (1998) 74 .

https://doi.org/10.1016/S0022-

3093(98)00011-8

168. Pekala, R. W., Mayer, S. T., Kaschmitter, J. L., \& Morrison, R. L. (1999). U.S. Patent No. 5,932,185. Washington, DC: U.S. Patent and Trademark Office.

https://patents.google.com/patent/US593 2185A/en

169. T. D. Tran, D. Lenz, K. Kinoshita and M. Droege, OPL496 (1997) 607. https://doi.org/10.1557/proc-496-607

170. R. W. Pekala and C. T. Alviso, MRS Pro., 270 (1992) 3.

https://doi.org/10.1557/proc-270-3

171. J. Farmer, D. Fix and G. Mack, (Lawrence Livermore National Lab., CA (United States), (1995).

https://www.osti.gov/biblio/86934

172. T. J. Welgemoed and C. F. Schutte, Desalination, $183 \quad$ (2005) 327. https://doi.org/10.1016/j.desal.2005.02.054

173. J. C. Farmer, C. Tracy, L. Murguia and C. Manteca, (1995).

https://www.citelec.org/eledrive/Afuelce llarticles/PATENTS/6309532.pdf
174. J. C. Farmer, D. V. Fix, G. V. Mack, R. W. Pekala and J. F. Poco, J. Electrochem. Soc., 143 (1996) 159. https://doi.org/10.1149/1.1836402

175. Farmer, J. C., Fix, D. V., Pekala, R. W., Nielsen, J. K., \& Volpe, A. M. (1996). LLNA CA. https://apps.dtic.mil/sti/citations/ADA34 9002

176. R. Kumar, S. Sen Gupta, S. Katiyar, V. K. Raman, S. K. Varigala, T. Pradeep and A. Sharma, Carbon, 99 (2016) 375. https://doi.org/10.1016/j.carbon.2015.12. $\underline{004}$

177. C.-M. Yang, W.-H. Choi, B.-K. Na, B. W. Cho and W. I. Cho, Desalination, 174 (2005) 125. https://doi.org/10.1016/j.desal.2004.09.006

178. K. Tang, T. Z. X. Hong, L. You and K. Zhou, J. Mater. Chem. A, 7 (2019) 26693.

https://doi.org/10.1039/C9TA08663C

179. Tanaka, S., \& Nishiyama, N. (2011). IntechOpen.

https://www.intechopen.com/chapters/17 $\underline{256}$

180. J. Yang and L. Zou, Micropor. Mesopor. Mater., $\quad 183 \quad$ (2014) 91. https://doi.org/10.1016/j.micromeso.201 $\underline{3.09 .003}$

181. J. Han, L. Shi, T. Yan, J. Zhang and D. Zhang, Environ. Sci.: Nano, 5 (2018) 2337. https://doi.org/10.1039/c8en00652k

182. Y. Li, Y. Liu, J. Shen, J. Qi, J. Li, X. Sun, J. Shen, W. Han and L. Wang, Desalination, $430 \quad$ (2018) 45. https://doi.org/10.1016/j.desal.2017.12.040

183. S.-H. Liu and Y.-H. Tang, $J$. Electroanal. Chem., 878 (2020) 114587. https://doi.org/10.1016/j.jelechem.2020. 114587

184. N. Sun, X. Zhang, C. Zhao, H. Wang, H. $\mathrm{Lu}$, S. Kang, H. Zhou, H. Zhang, H. Zhao and G. Wang, Chem Electro Chem, 5 (2018) 3873. https://doi.org/10.1002/celc.201801063 
185. M. Mi, X. Liu, W. Kong, Y. Ge, W. Dang and J. $\mathrm{Hu}$, Desalination, 464 (2019) 18. https://doi.org/10.1016/j.desal.2019.04.014

186. T. Wu, G. Wang, S. Wang, F. Zhan, Y. $\mathrm{Fu}, \mathrm{H}$. Qiao and J. Qiu, Environ. Sci.Technol. Lett., 5 (2018) 98. https://doi.org/10.1021/acs.estlett.7b005 40

187. W. Hu, F. Xie, Y. Li, Z. Wu, K. Tian, M. Wang, L. Pan and L. Li, Langmuir, 33 (2017) 13364.

https://doi.org/10.1021/acs.langmuir.7b0 $\underline{3175}$

188. H. Wang, D. Wei, H. Gang, Y. He, H. Deng, L. Hou, Y. Shi, S. Wang, W. Yang and L. Zhang, ACS Sustain. Chem. Eng., 8 (2020) 1129.

https://doi.org/10.1021/acssuschemeng.9 b06084

189. Y.-J. Kim and J.-H. Choi, Sep. Purif. Technol., 71 (2010) 70.

https://doi.org/10.1016/j.seppur.2009.10. 026

190. Z. Chen, C. Song, X. Sun, H. Guo and G. Zhu, Desalination, 267 (2011) 239. https://doi.org/10.1016/j.desal.2010.09.0 $\underline{33}$

191. S. Wang, D. Wang, L. Ji, Q. Gong, Y. Zhu and J. Liang, Sep. Purif. Technol., 58 (2007) 12.

https://doi.org/10.1016/j.seppur.2007.07. 005

192. M. Wang, Z.-H. Huang, L. Wang, M.-X. Wang, F. Kang and H. Hou, New J. Chem., 34 (2010) 1843.

https://doi.org/10.1039/c0nj00407c

193. H. Wang, H. Deng, Y. He, L. Huang, D. Wei, T. Hao, S. Wang, L. Jin and L. Zhang, Chem. Eng. J., 396 (2020) 125249.

https://doi.org/10.1016/j.cej.2020.125249
194. C.-C. Hsu, Y.-H. Tu, Y.-H. Yang, J.-A. Wang and C.-C. Hu, Desalination, 481 (2020) 114362. https://doi.org/10.1016/j.desal.2020.114 $\underline{362}$

195. A. S. Yasin, J. Jeong, I. M. A. Mohamed, C. H. Park and C. S. Kim, J. Alloys Compd., 729 (2017) 764.

https://doi.org/10.1016/j.jallcom.2017.09 .185

196. N.-L. Liu, S. Dutta, R. R. Salunkhe, T. Ahamad, S. M. Alshehri, Y. Yamauchi, C.-H. Hou and K. C. W. Wu, Sci. Rep., 6 (2016) 28847. https://doi.org/10.1038/srep28847

197. K. Rambabu, G. Bharath, A. Hai, S. Luo, K. Liao, M. A. Haija, F. Banat and M. Naushad, J. Clean. Prod., 272 (2020) 122626.

https://doi.org/10.1016/j.jclepro.2020.12 2626

198. L. Zhang, Y. Liu, T. Lu and L. Pan, J. Electroanal. Chem., 804 (2017) 179. https://doi.org/10.1016/j.jelechem.2017. 09.062

199. L. Li, L. Zou, H. Song and G. Morris, Carbon, 47 (2009) 775.

https://doi.org/10.1016/j.carbon.2008.11. $\underline{012}$

200. L. Zou, L. Li, H. Song and G. Morris, Water Sci. Technol., 61 (2010) 1227. https://doi.org/10.2166/wst.2010.879

201. C. Tsouris, R. Mayes, J. Kiggans, K. Sharma, S. Yiacoumi, D. DePaoli and S. Dai, Environ. Sci. Technol., 45 (2011) 10243. https://doi.org/10.1021/es201551e 